Article

\title{
Boosting the Timeliness of UAV Large Scale Mapping. Direct Georeferencing Approaches: Operational Strategies and Best Practices
}

\author{
Lorenzo Teppati Losè * ${ }^{\mathbb{D}}$, Filiberto Chiabrando $\mathbb{D}$ and Fabio Giulio Tonolo $\mathbb{D}$ \\ LabG4CH, Department of Architecture and Design (DAD)_Politecnico di Torino, Viale Mattioli 39, \\ 10125 Torino, Italy; filiberto.chiabrando@polito.it (F.C.); fabio.giuliotonolo@polito.it (F.G.T.) \\ * Correspondence: lorenzo.teppati@polito.it
}

Received: 31 July 2020; Accepted: 28 September 2020; Published: 30 September 2020

\begin{abstract}
The use of unmanned aerial vehicles (UAVs) is nowadays a standard approach in several application fields. Researches connected with these systems cover several topics and the evolution of these platforms and their applications are rapidly growing. Despite the high level of automatization reached nowadays, there is still a phase of the overall UAVs' photogrammetric pipeline that requires a high effort in terms of time and resources (i.e., the georeferencing phase). However, thanks to the availability of survey-grade GNSS (Global Navigation Satellite System) receivers embedded in the aerial platforms, it is possible to also enhance this phase of the processing by adopting direct georeferencing approaches (i.e., without using any ground control point and exploiting real time kinematic (RTK) positioning). This work investigates the possibilities offered by a multirotor commercial system equipped with a RTK-enabled GNSS receiver, focusing on the accuracy of the georeferencing phase. Several tests were performed in an ad-hoc case study exploiting different georeferencing solutions and assessing the 3D positional accuracies, thanks to a network of control points. The best approaches to be adopted in the field according to accuracy requirements of the final map products were identified and operational guidelines proposed accordingly.
\end{abstract}

Keywords: UAVs; SfM; PPK; RTK; NRTK; direct georeferencing

\section{Introduction}

Unmanned aerial vehicles (UAVs) represent, nowadays, a consolidated approach in several application fields. The evolution of these systems and the diffusion of their employment has followed several subsequent steps, as clearly detailed by Colomina ana Molina in [1], where the evolution of UAVs in the field of remote sensing and photogrammetry are reported and discussed. UAV application fields are further specified in [2], where the operational ranges of these platforms with respect to other geomatics techniques, and depending on the dimension and complexity of the surveyed area, are detailed and discussed. Nex and Remondino identified six main UAV application fields (that were addressed by several research groups), namely: agriculture [3-6], forestry [7-10], archaeology and architecture [11-17], the environment [18-21], emergency management [22-24], and traffic monitoring [25-28].

The diffusion of UAVs in the aforementioned application domains has boosted the related research and innovation activities that focused mainly on image georeferencing (given the positional accuracy requirements) and the automation of the image processing (considering the heterogeneity of end users skills). It is important to underline that the technological evolution was followed by a reduction of the purchasing costs, with a consistent expansion of the market and the diffusion of these platforms within different areas of society $[29,30]$, another factor that has boosted the research actions in this field. 
The main features that determined the success of UAVs, especially in comparison with manned airborne acquisitions are related to the reduction of flight elevation with obvious implication on the resolutions (on the other hand the limitations of flight height introduced by many regulations may be a limiting factor for the extent of the surveyed area), the adoption of different types of sensors (both image and range-based and sensitive to different parts of the electromagnetic spectrum), and the reduction of the costs. In general terms, UAVs are more flexible and can easily be deployed in the field, thus also enabling multitemporal analyses.

As far as the operational limitations are concerned, the main open issues are related to the extent of the surveyed area (due to the flight autonomy of these platforms as well as BVLOS (Beyond Visual line of Sight) limitations imposed by national regulations), the weight of the payload of a small-medium UAV (a critical element that affects the technical features of the installed sensors), and the influence of weather conditions (especially in terms of wind gusts).

The first two elements considered to define an UAV are the weight and dimension of the platform, generally used to categorize UAVs and consequently the tasks that they can solve. The weight parameter is the element used in national and international regulation to define the category in which a determined UAV can operate. The Italian regulation for the use of UAVs, issued and monitored from the Italian Civil Aviation Authority (ENAC), presents a specific series of regulations depending on the MTOW (maximum take-off weight) of the considered platform. This approach has also been adopted in the European regulation and in other countries as reported in [31]. The different European member states are adapting their regulations to the new standards issued by EASA (European Union Aviation Safety Agency); a complete list of the references to actual regulation and National Aviation Authorities in the different European countries can be found on the EASA website at [https://www.easa.europa.eu/domains/civil-drones/naa]. For the tests presented in this manuscript, only platforms with a MTOW under $2 \mathrm{~kg}$ were used; the relevant regulations are reported in Section II of the third edition of the Italian regulation [32].

The physical structure of the platform is used to further classify UAV platforms, namely fixed-wing and multirotor platforms. This classification is not merely formal, since the choice of the category to be used highly depends on the application requirements and the environmental conditions. Fixed-wing solutions allow for larger areas to be covered in a limited amount of time, while multirotor systems are generally easily deployable in the field (especially in terms of takeoff and landing), more flexible and maneuverable, and less affected by weather conditions [1].

This manuscript focused on a specific approach (direct georeferencing) to enhance, mainly in terms of timeliness and positional accuracy, the georeferencing of images acquired by a multi-rotor platform. Background, context, and details on this specific topic are provided in the following paragraphs.

\subsection{Unmanned Aerial Vehicles (UAVs) and Structure from Motion (SfM) Approaches}

Image acquisition and UAVs have been strictly connected since the first development of unmanned aerial platforms. This was demonstrated by the parallel development of COTS (Commercial Off The Shelf) cameras to be integrated with aerial platforms, enabling the use of high resolution optical (visible) sensors as UAVs payloads for photogrammetric applications [33]. Due to their technical features, these kinds of cameras are not always suitable for high accuracy photogrammetric application and an assessment on their performances and an accurate calibration is generally a crucial step of the overall photogrammetric processing. The enhancement of automated photogrammetric pipelines (generally based on Structure from Motion (SfM) approaches) represent, therefore, another crucial step.

Accordingly, in the last years, several studies have focused on the use of UAVs to generate both 3D models and added-value metric products by means of SfM approaches. These have addressed different aspects (e.g., the optimization of flight planning and image acquisition phases [34,35], the use of oblique images [36], the optimization of the control points configuration [37-39], the assessment of geometric accuracy of photogrammetric products [40], and the camera calibration [41,42]). 


\subsection{Georeferencing Issues in UAVs Photogrammetric Pipeline}

The photogrammetric process benefitted from a fast process of automatization in the past years, leading to a reduction in the time needed to complete the process as well as a lower level of human intervention. Nevertheless, the georeferencing phase is still almost fully manual. Additionally, in the most updated SfM approaches, this phase is the most time consuming and less automated. The common approach to carry out the georeferencing phase is referred to as indirect georeferencing and foresees the use of GCPs (Ground Control Points) and CPs (Check Points) [43]. The most significant disadvantage of this approach is that GCPs and CPs need to be measured in the field (using traditional topographic techniques or by means of GNSS receivers) as well as pre-positioned in case natural targets are not suitable. This step of fieldwork is, for sure, one of the most time consuming and depending on the accessibility of the area, it may be unfeasible. Moreover, the use of GCPs in the data processing phase is also time consuming since an operator needs to manually identify the points on the images in order to link the map coordinates with the image ones [38]. Solutions based on the automatic/semi-automatic recognition of artificial targets to be used as GCPs already exist: nevertheless, the fieldwork phases of target positioning and measuring still represent a time-consuming operation.

Different environmental conditions can limit or constrain the positioning and measuring of control points in the field: the safety of the operators (e.g., in an emergency context or in dangerous areas), inaccessibility of the surveyed area, or simply limited resources in terms of time, operators, and funds. The georeferencing of UAV acquired images requires at least the use of four GCPs [37], however, the use of a higher number of GCPs is generally advised to introduce redundancy and to better estimate the camera IOP (Interior Orientation Parameters). The number and spatial distribution of GCPs (to be defined also depending on the extent of the area to be surveyed) is another crucial element to guarantee a homogenous accuracy of the generated photogrammetric products. Nevertheless, for the aforementioned environmental reasons, a correct configuration of the network of GCPs cannot always be achieved and often none or only a limited number of GCPs can be positioned and measured.

To cope with the aforementioned issues, in the last years, several research groups have developed strategies to optimize the exterior orientation phase. Some authors, like in [44], have focused on overcoming the use of GCPs using co-registration approaches among multi-temporal datasets; other contributions $[37,38,45]$ have focused on the optimization of the number and position of GCPs.

More recently, the research has focused on the direct georeferencing approach (that does not require any GCP and has been commonly used for several years for manned aerial photogrammetric surveys), which was enabled by the availability of small survey-grade GNSS (Global Navigation Satellite System) receivers and IMUs (Inertial Measurement Units) that can be embedded on UAVs and used to track the platform during the flight [46]. Direct georeferencing is very attractive for an overall optimization of UAV-based photogrammetric survey, however, different issues still remain and the final accuracy still needs to be carefully assessed, especially for consumer-grade UAV platforms. An important step for the success of direct georeferencing approaches is related to the calibration and synchronization of the different sensors installed on board, as reported in [47].

\subsection{Interior Orientation Parameters (IOP) Estimation and Its Relation with Georeferencing Approaches}

In modern SfM approaches, the phase of IOP estimation is solved during the first image alignment process (also known as relative orientation) and refined in the BBA (Bundle Block Adjustment) process, where scene geometry, camera EOP (external orientation parameters), and camera IOP estimation are solved simultaneously. In the camera calibration step, the camera model is generally based on the central projection and the modelling of the camera is based on different models such as Brown's model [48,49], Fraser's model [50], or other polynomial models [51]. The IOPs describe the following parameters: focal length $(f)$, principal points offset $(c x, c y)$, radial distortion $\left(k_{1}-k_{4}\right)$, tangential distortion $\left(p_{1}-p_{4}\right)$ and skew $\left(b_{1}, b_{2}\right)$. These parameters are used to model the physical configuration of the different elements that compose the sensor lens and their definition is crucial to achieving a high geometric accuracy. Several calibration techniques have been refined and tested, including solutions tailored 
to UAV photogrammetry as reported in $[33,47,52]$. Three main approaches were considered in the framework of this research: a laboratory calibration certificate provided by the UAV manufacturer; the on-the-job self-calibration; and finally the use of a calibration certificate estimated during previous photogrammetric processing. Camera self-calibration is affected by different factors such as the geometry of the performed acquisition, the percentage of image overlap, flight altitude changes, the inclusion of oblique images, and the number and position of GCPs [41,53-55].

As already stressed by the referenced literature and as will be further discussed in this paper, a correct estimation of IOP is particularly important when adopting direct georeferencing approaches.

\subsection{Direct Georeferencing Approaches}

Different solutions can be adopted for the georeferencing of UAV imagery without the use of any GCP (i.e., by means of a direct georeferencing approach). As reported by [55], these approaches were made possible mainly thanks to the improved quality of the UAVs onboard sensors, namely the GNSS receiver (low cost high accuracy double frequency and multi-constellation receiver are available nowadays) and the IMU (Inertial Measurement Unit). The integration of these two categories of sensors allows us to estimate the position and orientation of the platform at the time of the acquisition, enabling a direct georeferencing approach [56]. IMU measurements are mainly used to estimate the attitude of the platform during the flight and are integrated in the timestamp file that is then used to reconstruct camera orientation and offset with respect to the APC (Antenna Phase Center) at the time of image acquisition.

More specifically, direct georeferencing can be achieved following two main approaches: (i) PPK (Post-Processed Kinematic) and (ii) RTK (Real-Time Kinematic) or NRTK (Network Real-Time Kinematic).

In the PPK approach, the correction of UAV positions recorded by the GNSS receiver during the flight and the estimation of the camera positions are carried out after the data acquisition phase. This solution allows precise ephemeris data to be used in the computations, theoretically achieving more accurate results.

In the RTK approach, the coordinates measured by the onboard GNSS are corrected with the information sent by a base station, and the camera positions are estimated in real-time. The GNSS base station can be a receiver setup in the field or a virtual station created by a network of CORSs (Continuously Operating Reference Stations), whose corrections are sent via a GNSS Networked Transport of RTCM via Internet Protocol (NTRIP). The latter approach is known as the NRTK solution. This solution requires a stable radio connection as well as Internet connectivity.

All the above-described approaches allow to reach, in theory, a few centimeters of positional accuracy of the value added products and several related studies are available in the literature [37,55,57-63]. Despite the rich and recent available literature, different issues still remain open, especially when working with commercial and mass-market UAVs systems including a proper assessment of the claimed positional accuracies. Moreover, other issues related to operational strategies to be adopted in the field (e.g., flight plan, camera orientation, accuracy assessment of the products, etc.) need to be further addressed by the research community.

\subsection{Aims and Structure of the Research}

The research outcomes presented in this manuscript are connected to two previous experiences of the authors $[64,65]$ that will be briefly reported in the next section, covering different case studies with both fixed-wing and multi-rotor platforms based on different approaches. To complement the experience related to these previous works, a specific set of tests was designed to consistently verify: (i) the positional accuracy of value added products based on images acquired by a commercial platform, the DJI Phantom 4 RTK; (ii) the different direct georeferencing strategies that can be adopted in the field; and (iii) the operational guidelines and best practices that can be followed.

The main specifications of the platform with the main features of the test site are provided in Section 2. Details on the acquisition planning and execution, including the setup of the topographic 
network, the measurement of the control points, and the design of the different flight paths depending on the adopted direct georeferencing solution are also reported in Section 2. The processing strategies of the different datasets acquired are also detailed and discussed in the same section, highlighting the issues faced during this phase and the adopted solutions.

The results of the accuracy assessments performed after the processing phase are shown and discussed in Section 3.

Finally, final remarks related to the best direct georeferencing strategies and related accuracies are presented in Section 4.

\section{Materials and Methods}

\subsection{Preliminary Experiences}

With the goal to provide a comprehensive overview of the direct georeferencing topic, it is considered useful to provide a summary of two previous experiences also related to different categories of UAV (fixed-wing), other applications (emergency management), and further case studies (details can be retrieved in the related references).

A specific test was connected to the activities of the task force of Politecnico of Turin after the 2016 earthquake in Central Italy [64]. The aim of this work was to test the PPK capability of a fixed-wing platform, the eBee plus by SenseFly, in a post-disaster scenario. Indeed, in this specific scenario, the measurement of control points is particularly complex and the safety of the operators involved in the field activities must be carefully considered. The tests presented in this research were carried out in the city of Accumoli (RI), one of the Italian villages severely damaged by the 2016 earthquake. In this first experience, the direct georeferencing approach was tested by means of two different strategies: using the raw GNSS observation (without any post processing) acquired during the acquisition and the post-processed PPK data. Furthermore, different GCPs/CPs configurations were tested for both the georeferencing strategies: (i) 0 GCPs (direct georeferencing) and $31 \mathrm{CPs}$, (ii) five GCPs and $26 \mathrm{CPs}$, and (iii) 13 GCPs and 18 CPs.

A summary of the results achieved in this research is reported in Table 1.

Table 1. Positional accuracy of the different direct georeferencing strategies tested with the eBee Plus at the site of Accumoli, from [65].

\begin{tabular}{|c|c|c|c|c|c|c|c|}
\hline & & \multicolumn{3}{|c|}{ Raw GNSS (m) } & \multicolumn{3}{|c|}{ PPK (m) } \\
\hline & & Mean & StDev & RMSE & Mean & StDev & RMSE \\
\hline DG & $X$ & -1.103 & \pm 0.108 & 1.108 & -0.006 & \pm 0.028 & 0.029 \\
\hline 0 GCPs & $\mathrm{Y}$ & -0.844 & \pm 0.130 & 0.853 & 0.014 & \pm 0.014 & 0.020 \\
\hline $31 \mathrm{CPs}$ & $\mathrm{Z}$ & -3.917 & \pm 0.468 & 3.945 & -0.082 & \pm 0.030 & 0.087 \\
\hline \multirow{3}{*}{$\begin{array}{l}5 \mathrm{GCPs} \\
26 \mathrm{CPs}\end{array}$} & $X$ & 0.003 & \pm 0.031 & 0.031 & 0.002 & \pm 0.026 & 0.026 \\
\hline & $\mathrm{Y}$ & 0.003 & \pm 0.016 & 0.017 & -0.003 & \pm 0.013 & 0.013 \\
\hline & $\mathrm{Z}$ & 0.002 & \pm 0.070 & 0.069 & 0.008 & \pm 0.025 & 0.026 \\
\hline \multirow{3}{*}{$\begin{array}{c}13 \text { GCPs } \\
18 \text { CPs }\end{array}$} & $x$ & 0.005 & \pm 0.024 & 0.025 & 0.000 & \pm 0.002 & 0.002 \\
\hline & $\mathrm{Y}$ & 0.000 & \pm 0.012 & 0.012 & 0.000 & \pm 0.001 & 0.001 \\
\hline & $\mathrm{Z}$ & -0.003 & \pm 0.032 & 0.032 & 0.000 & \pm 0.003 & 0.003 \\
\hline
\end{tabular}

The results of this test show that without the use of any ground control points, it is possible to reach a centimeter level accuracy using a UAV equipped with a high performance GNSS receiver and adopting a PPK approach (while with raw GNSS measurements without any post processing only an accuracy of few meters can be achieved). The introduction of a few GCPs is crucial only with raw GNSS data.

A second preliminary experiment was represented from a series of tests carried out in 2019 on a cultural heritage asset near Turin (Italy), the Castellazzo of Caluso [65]. In this work, the same multi-rotor platform used for the test presented in this manuscript was used and the performed 
tests were particularly important to set up the methodology and the tests that are part of the present investigation.

Two different direct georeferencing strategies were tested, PPK and NRTK, with nadiral images only. The use of only nadiral images generated some issues in the phase of camera calibration and different strategies to deal with this issue were proposed, analyzed, and discussed. The main results for the direct georeferencing approaches reported in this research are detailed in Table 2.

Table 2. Positional accuracy of the different direct georeferencing strategies tested with the Phantom 4 RTK in the site of Caluso, from [66].

\begin{tabular}{ccccc}
\hline & & $\Delta \mathbf{X}(\mathbf{m})$ & $\Delta \mathrm{Y}(\mathrm{m})$ & $\Delta \mathrm{Z}(\mathrm{m})$ \\
\hline \multirow{2}{*}{ PPK. 0 GCPs, 17 CPs } & Mean & 0.002 & -0.006 & 0.727 \\
& StDev & \pm 0.033 & \pm 0.031 & \pm 0.108 \\
PPK. 1 GCPs, 16 CPs & Mean & -0.003 & 0.002 & -0.023 \\
& StDev & \pm 0.017 & \pm 0.019 & \pm 0.031 \\
NRTK. 0 GCPs, 17 CPs & Mean & 0.054 & 0.017 & -0.068 \\
& StDev & \pm 0.063 & \pm 0.035 & \pm 0.039 \\
\hline
\end{tabular}

In both experiments, the accuracy of the different georeferencing strategies was assessed by analyzing the deviation between the coordinates of the control points measured in the field and the coordinates of the same points extracted from the photogrammetric processing.

\subsection{The Deployed Platform and the Test Site}

The COTS. This specific commercial solution was chosen since it is equipped with a multifrequency and multi-constellation GNSS receiver with RTK capabilities that records raw GNSS observations at a sampling rate of $5 \mathrm{~Hz}$. Exploiting this observation file and thanks to the IMU, the platform also stores a text file named timestamp, which contains the information about the camera position and orientation at the exposure time during the flight. Second, similar to other more expensive platforms of the company, the Phantom 4 RTK can be directly linked to a GNSS base station for the transmission of real time differential correction including the DJI D-RTK 2 station, a GNSS base station produced by DJI itself. The main characteristics of the platform are reported in Table 3, while the main technical features of the D-RTK 2 base station are reported in Table 4.

Table 3. Main characteristics of the DJI Phantom 4 RTK [67].

\begin{tabular}{|c|c|c|c|c|c|}
\hline \multicolumn{6}{|c|}{ Platform main characteristics } \\
\hline Weight & $1391 \mathrm{~g}$ & $\begin{array}{l}\text { Diagonal } \\
\text { Distance }\end{array}$ & $350 \mathrm{~mm}$ & Max Flight Time & $\approx 30 \mathrm{~min}$ \\
\hline \multicolumn{6}{|c|}{ Camera main characteristics } \\
\hline Sensor & $1^{\prime \prime} \mathrm{CMOS} 20 \mathrm{MP}$ & $\begin{array}{c}\text { Lens Field of } \\
\text { View }\end{array}$ & $84^{\circ}$ & Focal Length & $8.8 \mathrm{~mm} / 24 \mathrm{~mm}^{1}$ \\
\hline $\begin{array}{c}\text { Gimbal } \\
\text { stabilization }\end{array}$ & 3-axis (tilt, roll, yaw) & Gimbal pitch & $-90^{\circ}$ to $+30^{\circ}$ & & \\
\hline \multicolumn{6}{|c|}{ GNSS main characteristics } \\
\hline $\begin{array}{c}\text { GNSS } \\
\text { constellation }\end{array}$ & $\begin{array}{l}\text { GPS, GLONASS, } \\
\text { Galileo }\end{array}$ & $\begin{array}{l}\text { GNSS } \\
\text { frequency }\end{array}$ & $\begin{array}{c}\text { GPS:L1/L2 } \\
\text { GLONASS:L1/L2 } \\
\text { Galileo:E1/E5a }\end{array}$ & $\begin{array}{l}\text { Positioning } \\
\text { accuracy }\end{array}$ & $\begin{array}{l}\text { Vertical } 1.5 \mathrm{~cm}+1 \mathrm{ppm} \text {; } \\
\text { Horizontal } 1 \mathrm{~cm}+1 \mathrm{ppm}\end{array}$ \\
\hline
\end{tabular}

Table 4. Main characteristics of the DJI D-RTK 2 [68].

\begin{tabular}{|c|c|c|c|}
\hline \multicolumn{4}{|c|}{ D-RTK 2 Main Characteristics } \\
\hline GNSS frequency & $\begin{array}{c}\text { GPS: L1 C/A, L2, L5 } \\
\text { BEIDOU: B1, B2, B3 } \\
\text { GLONASS: F1, F2 } \\
\text { Galileo: E1, E5A, E5B }\end{array}$ & Positioning Update Rate & $\begin{array}{c}1 \mathrm{~Hz}, 2 \mathrm{~Hz}, 5 \mathrm{~Hz}, 10 \mathrm{~Hz}, \\
\text { and } 20 \mathrm{~Hz}\end{array}$ \\
\hline $\begin{array}{l}\text { Positioning Accuracy } \\
\text { (Single Point) }\end{array}$ & $\begin{array}{l}\text { Horizontal: } 1.5 \mathrm{~m} \\
\text { Vertical: } 3.0 \mathrm{~m}\end{array}$ & Positioning Accuracy (RTK) & $\begin{array}{l}\text { Horizontal: } 1 \mathrm{~cm}+1 \mathrm{ppm} \\
\text { Vertical: } 2 \mathrm{~cm}+1 \mathrm{ppm}\end{array}$ \\
\hline
\end{tabular}


Among the main scientific papers focused on the use of this platform, Ref. [33] compared the performances of a Phantom 4 Pro and a Phantom 4 RTK; in [68,69], the authors tested different direct georeferencing strategies for the monitoring of a coastal area; Ref. [70] created a test field with points of known coordinates to evaluate the accuracy of different GNSS flight modes; and finally, Ref. [63] evaluated the results achievable with the Phantom 4 RTK in different operative scenarios and by adopting different direct georeferencing strategies.

In the research presented in this manuscript, some issues that were not tackled or were only partially addressed in the aforementioned research were considered and analyzed. Specifically, two approaches have been tested: (i) the PPK approach using a third part GNSS receiver placed on a point of known coordinates, and (ii) the RTK approach using the DJI antenna D-RTK 2 (DRTK). Additionally, an overview of all the different direct georeferencing approaches and an evaluation of their performances covering the same case study are still missing in the literature.

The presented results are related to a series of tests carried out in the area of the Tempio di Diana that is part of the gardens of the Reggia di Venaria Reale [https://www.lavenaria.it/en], and is located $25 \mathrm{~km}$ north from Turin. The Reggia di Venaria was one of the historical residences of the Royal House of Savoy and since 1997 has been included on the UNESCO World Heritage List [https://whc.unesco.org/en/list/].

More specifically, the test site (Figure 1) was located in the western part of the gardens that hosts the remains of the structure of the Temple of Diana, an XVII century building that was part of the project of the gardens realized from Amedeo di Castellamonte. The temple was then demolished in the 18th century due to a change in the esthetics of garden composition [71]. Recently, the area was part of a project of restoration and valorization that defined its actual conformation. This area was chosen for two main reasons: first, it encompasses different categories of features that are possible to find in a real case scenario (both natural and humanmade), and second, it presents various changes in the elevation component across the area. Both these characteristics are generally not present in a standard UAV flight area, which usually shows a flat surface and the absence of humanmade features. The extent of the test area is limited to $\sim 0.5 \mathrm{~km}^{2}$, which is considered an acceptable compromise in terms of cost-benefit balance in a research context. The size of the area of interest and the time required to survey it (two batteries are required for each flight test) is comparable to a real case scenario when using multi-rotor platforms (e.g., survey of a cultural heritage site). Further tests on wider areas using a fixed-wing RTK UAV platform are already planned.

Before the acquisition phase, it was necessary to setup a network of control points to be used in the subsequent phases of data processing and positional accuracy assessment. The first step consisted of the materialization and measurement of two vertices. The vertices were measured through a static GNSS acquisition (one hour) with two Geomax Zenith 35 GNSS receivers. The observations collected in the field were then integrated with the data derived from the permanent network of CORSs of the SPIN3 GNSS [https://www.spingnss.it/spiderweb/frmIndex.aspx], the positioning service of Piemonte, Lombardia, and Valle d'Aosta regions. The two-vertices network was thus adjusted and the final accuracy of the 3D coordinates was lower than one centimeter for both points. The network coordinates and all the following topographic measurements referred to the UTM 32N WGS84 projected coordinate system. The second operation in the field was the positioning and measuring of a set of 15 artificial checkboard targets, homogenously distributed across the area. In order to obtain a set of points with centimetric accuracy, the targets were measured following the traditional side shot approach using a total station (Leica Viva Multi Station): the coordinates of the points were then calculated with the Microsurvey StarNet software solution. The position of the two vertices and the distribution of the targets in the area of the Tempio di Diana is shown in Figure 2. 


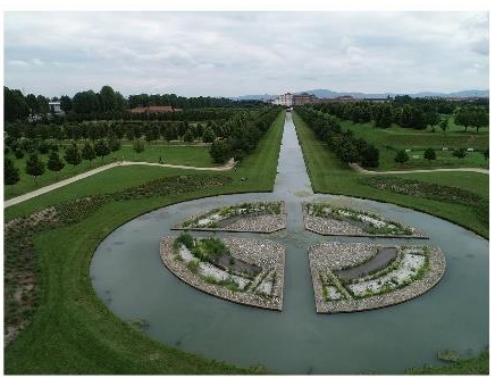

(a)

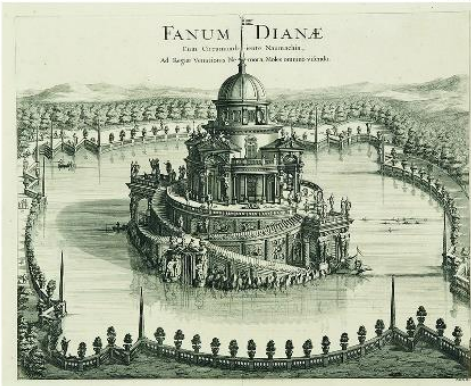

(b)

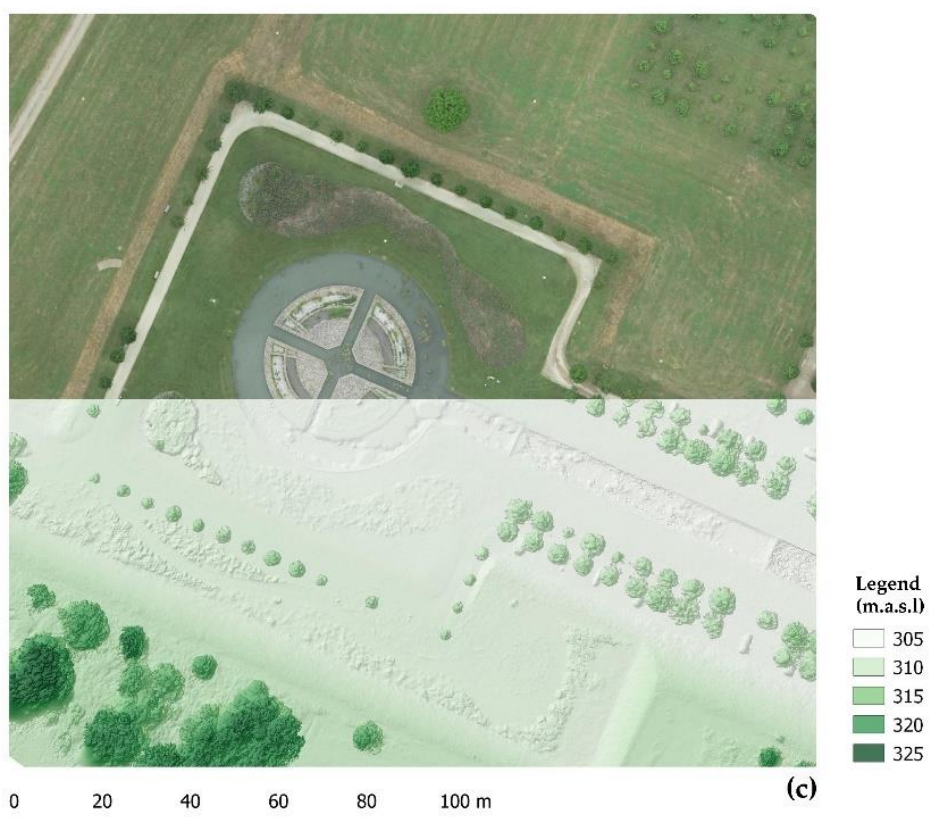$$
\text { (1) }
$$

Figure 1. The area of the Temple of Diana. An aerial image of the area (a), an 18th century representation (b) and an extract of DSM and orthoimage of the area (c).
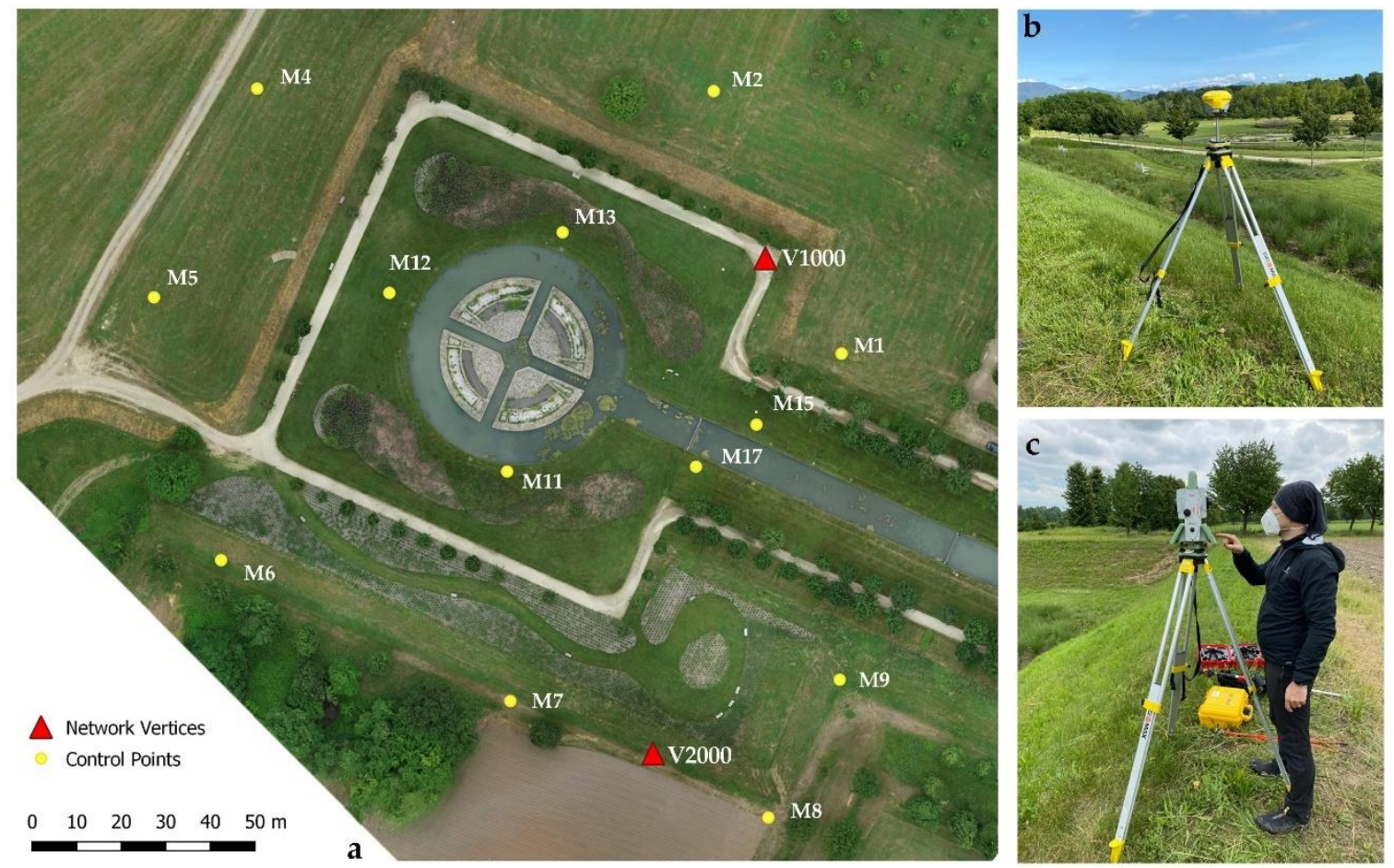

Figure 2. The two vertices of the network (a, red triangles) and the set of control points (a, yellow points). Some of the measurement phases on the field $(\mathbf{b}, \mathbf{c})$.

\subsection{Flight Plan and Image Acquisition Strategies}

The second step of the fieldwork was the execution of the different flights for the acquisition of the images to be processed with a SfM approach. The flights were planned and carried out with the DJI Pilot software, the native DJI application for the Phantom 4 RTK. It is important to underline that the raw GNSS observations are stored only in automatic flight mode, whereas they are not stored if the $\mathrm{UAV}$ is manually piloted. In order to achieve a complete reconstruction of the area of the Tempio di 
Diana, two different flight plans were designed and carried out for each of the flight strategies that are described in the following section. The main characteristics of the two flight plans are summarized in Table 5, while the flight schemes are shown in Figure 3.

Table 5. Main parameters of the flight plans programmed in the area of Tempio di Diana.

\begin{tabular}{cccccc}
\hline ID & Altitude & Overlap & Camera Orientation & No. of Images & Flight Speed \\
\hline Flight A (grid) & $60 \mathrm{~m}$ & $75 \%$ Front, 70\% Lateral & Nadiral & 136 & $2.5 \mathrm{~m} / \mathrm{s}$ \\
Flight B (double grid) & $60 \mathrm{~m}$ & $80 \%$ Front, 75\% Lateral & $45^{\circ}$ & 229 & $3 \mathrm{~m} / \mathrm{s}$ \\
\hline
\end{tabular}
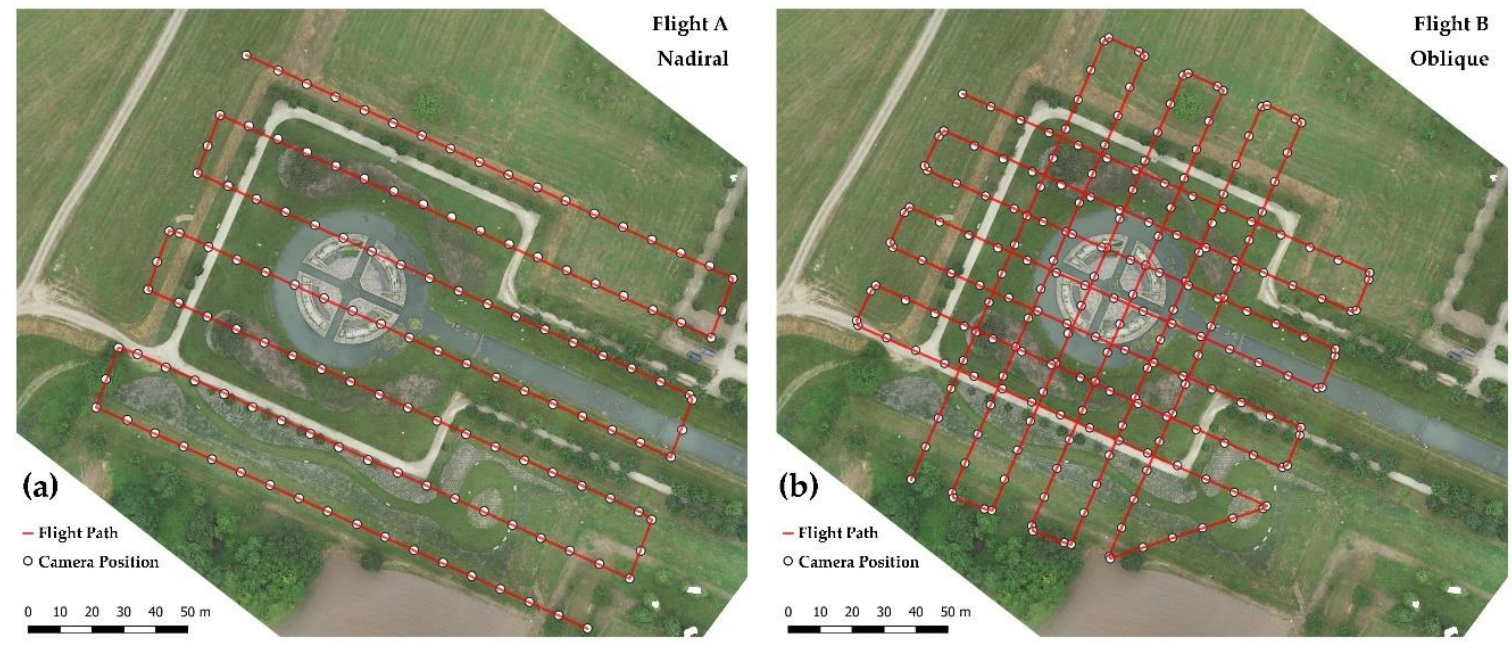

Figure 3. Flight plans of the flights performed at the Tempio di Diana. Flight A with a nadiral camera configuration (a) and Flight B with an oblique camera configuration (b).

The expected GSD (ground sampling distance) from the combination of these two flights plans is about $1.5 \mathrm{~cm} /$ pixel.

\subsection{Positioning Solutions Adopted during the Flight Tests}

The two flight schemes presented in the previous paragraph were performed three times, for a total of six flights, to exploit the different GNSS positioning solutions for the georeferencing of the acquired photogrammetric block. A summary of the photogrammetric flights is reported in Table 6 .

Table 6. Positioning solution adopted during the different flights performed.

\begin{tabular}{|c|c|}
\hline Flight ID ${ }^{1}$ & Positioning Solution \\
\hline Flight 1 & Standalone (Position acquired only by the onboard GNSS receiver) \\
\hline Flight 2 & NRTK (Position refined in real-time through the correction obtained via NTRIP) \\
\hline Flight 3 & $\begin{array}{l}\text { (D)RTK (Position refined thanks to the corrections sent by a GNSS master station in the } \\
\text { field, the D-RTK } 2 \text { receiver set on a point of known coordinates in this specific case) }\end{array}$ \\
\hline
\end{tabular}

Flight 1 was completed following the most common and consolidated approach for UAV-based mapping (i.e., the use of the position of the onboard GNSS receiver to geotag in real-time the images at the acquisition time). Nevertheless, having available an RTK-enabled GNSS receiver, the raw GNSS data can be further processed by means of a PPK approach.

This solution can generally be post-processed using two different approaches: the use of GPCs and raw GNSS data or a PPK-based direct georeferencing approach, knowing that a direct georeferencing approach without any GNSS post-processing would lead to poor positioning accuracies (few meters accuracy).

The acquisition during Flight 2 was carried out with an active connection of the platform to a network of CORSs, adopting a solution known as NRTK. The UAV is connected to an NTRIP service 
streamed by the radio controller and received through Internet connectivity. This connection ensures the availability of real-time corrections that allow the platform positioning accuracy to be enhanced, and consequently the quality in the geotagging of the acquired images. This approach is feasible if two main requirements are met: first of all, the presence of a network of CORSs covering the area (including a subscription if required) and the presence of a stable Internet connection.

Finally, Flight 3 was completed using as a positioning solution the DRTK enabled by the DJI GNSS station. This solution is actually achievable only using the D-RTK 2 GNSS receiver as a base station (no other receivers could be used at the moment) and can be adopted with two different strategies. The first strategy requires the D-RTK 2 to be placed on a point of known coordinates in the area of the survey, while the second one allows the GNSS station to be positioned on any point. The D-RTK 2 streams real-time corrections needed to enhance the UAV positioning accuracy; in general terms, more accurate results should be achieved if the coordinates of the point on which the station is placed are known (and set in the flight controller app). The drawback of this strategy is the need for at least one point of known coordinates in the area of interest. Moreover, the accuracy of the coordinates of the reference point can directly influence the accuracy of the coordinates stored in the geotag of the acquired images. For the test presented in this manuscript, the solution that foresees the use of a point of known coordinates was adopted: the D-RTK GNSS receiver was placed on one of the two reference network's vertices.

\subsection{IOP Estimation, Camera Calibration, and Ground Control Points (GCPs)}

The issues connected with the IOP estimation when adopting direct georeferencing approaches were tackled following different strategies, also thanks to previous experiences reported in the literature. As published in $[47,72]$, the absence of GCPs can lead to a weak or wrong IOP estimation during the self-calibration phase. Possible solutions to solve these issues require the use of a limited number of GCPs to strengthen both the georeferencing phase and the camera IOP estimation or the exploitation of an existing calibration certificate.

DJI provides an IOP certificate specific to each Phantom 4 RTK platform: this information is directly embedded in the EXIF (exchangeable image file format) of each image and includes focal length, principal point, $k_{1}, k_{2}, k_{3}, p_{1}$, and $p_{2}$. However, as reported in a previous paper [65], the certificate provided by the producer is characterized by some inconsistencies with respect to the IOP estimated through a self-calibration approach. The outcomes presented in this paper highlight that small changes in the values of the IOP can highly affect the accuracy of the photogrammetric block orientation when no GCPs are included in the processing. In the same research, another key element was underlined: the adoption of oblique images makes the camera self-calibration step more robust (all the more reason, if only nadiral images are used, where a correct estimation of IOP is crucial).

As far as the case study is concerned, during the processing of the datasets, different approaches have been tested. The first approach foresees the inclusion in the processing of one or three GCPs, assessing the impact on both the estimated IOP and the RMSE (Root Mean Square Error) on the CPs used to assess the 3D accuracy of the block orientation. The second approach was based on the use of a calibration certificate obtained through a self-calibration approach based on the processing of datasets previously acquired with the same UAVs. Two different set of parameters have been used: one calculated months before the analyzed dataset ([65], Table 7, second column) and one obtained through an on-site self-calibration in the same area (Table 7, third column). The pre-calibration provided by DJI (Table 7, first column) was not used due to the poor results obtained in previous experiences (as previously mentioned) and other considerations highlighted in [69]. 
Table 7. IOP of the Phantom RTK embedded camera (Agisoft Metashape was used for the self-calibration). Values represented by "/" are negligible.

\begin{tabular}{|c|c|c|c|c|c|}
\hline IOP & $\begin{array}{l}\text { DJI Pre-Calibration } \\
\text { (Not Used) }\end{array}$ & $\begin{array}{l}\text { PC_1_Caluso } \\
\text { Self-Calibration }\end{array}$ & $\begin{array}{c}\text { PC_1_Error on Estimation } \\
\text { of Parameters }\end{array}$ & $\begin{array}{l}\text { PC_2_Venaria } \\
\text { Self-Calibration }\end{array}$ & $\begin{array}{c}\text { PC_2_Error on Estimation } \\
\text { of Parameters }\end{array}$ \\
\hline F [pixel] & 3635.190 & 3620.157 & 0.35 & 3627.406 & 0.048 \\
\hline k1 & -0.264 & -0.266 & 1 & -0.266 & 1 \\
\hline k2 & 0.111 & 0.114 & i & 0.108 & i \\
\hline k3 & -0.038 & -0.043 & I & -0.031 & I \\
\hline k4 & 0.000 & 0.008 & l & 0.000 & / \\
\hline cx [pixel] & 2.480 & -4.262 & 0.016 & -4.468 & 0.016 \\
\hline cy [pixel] & 9.690 & 6.526 & 0.012 & 6.362 & 0.03 \\
\hline p1 & 0.000 & -0.001 & 1 & -0.001 & 1 \\
\hline p2 & -0.001 & 0.000 & 1 & -0.001 & i \\
\hline b1 & 0.000 & -0.350 & 1 & -0.099 & i \\
\hline b2 & 0.000 & 0.311 & 1 & -0.035 & 1 \\
\hline
\end{tabular}

\subsection{Processing of the Acquired Datasets Following Different Strategies}

A first step, preliminary to the processing of the data using direct georeferencing approaches, consisted of the processing of the three flights (Flights 1,2, and 3) by adopting standard strategies. The three flights were processed with the well-known photogrammetric software Agisoft Metashape (v1.6.2.10247) and this step was crucial to the following phases. In order not to repeat the identification of the control points in the oriented images, thus adding an uncertainty caused by the operators when pinpointing $(\mathrm{G}) \mathrm{CPs}$, it was decided to follow a different strategy. The points were thus identified in this preliminary standard processing and their image and map coordinates were exported in a XML file for all three flights. This file can be imported in other projects containing the same set of images, allowing us to also obtain the RMSEs of the CPs, thanks to a comparison between the coordinates measured in the field and the coordinates of the same control points estimated through the direct georeferencing approach.

\subsubsection{Post Processed Kinematik (PPK)}

The processing of the data through a PPK method is performed following a two-step approach. The first step of this approach foresees the post-processing of the raw GNSS observation recorded and stored during the flight. This step requires the availability of observations acquired from a base station during the UAVs' flight and a software solution to perform the processing. Considering that different data can be used as a base station, several solutions were tested: data acquired in the field from a third part receiver (Geomax Zenith 35 positioned in one of the reference network vertex); observations collected from one of the CORSs of the SPINGNSS network; and finally a Virtual RINEX created in the center of the surveyed area thanks to the service provided from the same virtual network service. The software solution chosen for the PPK processing is the opensource package RTKLIB version 2.4.3 [http://www.rtklib.com/]. The processing was performed using the RTKPOST module of RTKLIB using as input the raw GNSS observations acquired by the base station and the UAV as well as precise ephemerides downloaded from [https://cddis.nasa.gov/]. For the processing only GPS and GLONASS constellations were used and the elevation cut off angle was set to $15^{\circ}$. For all the PPK tests, the quality of the solution (automatically estimated as standard deviation by the software) was generally below a half centimeter for the planimetric components and below one centimeter for the altimetric component.

The second step of this approach consists of the interpolation of the camera positions starting from the platform positions after the PPK processing in RTKLIB. Crucial for this operation is the so-called timestamp file, acquired and stored by the Phantom 4 RTK. This file contains the name of the acquired images, their exposure time, and the offset between the APC and sensor center. To complete this step, a pre-compiled freely distributed spreadsheet created by the Aerotas Company [https://www.aerotas.com/] was used. This spreadsheet interpolates the data derived from the RTKLIB PPK computation at the different timestamps, allowing the camera coordinates to be estimated. 
These image coordinates were then imported in the photogrammetric software to perform the image block orientation.

Several configurations of PPK processing were tested, as reported in Table 8.

Table 8. PPK processing strategies for Flight 1.

\begin{tabular}{lccccccc}
\hline ID & Flight Plan ${ }^{1}$ & Flight ID & $\begin{array}{c}\text { Base } \\
\text { Station }\end{array}$ & $\begin{array}{c}\text { Base Station } \\
\text { Distance }\end{array}$ & $\begin{array}{c}\text { No. of } \\
\text { GCPs }\end{array}$ & $\begin{array}{c}\text { No. of } \\
\text { CPs }\end{array}$ & $\begin{array}{c}\text { Camera } \\
\text { Calibration }{ }^{2}\end{array}$ \\
\hline PPK_1 & A + B & Flight 1 & V2000 & $<1 \mathrm{Km}$ & 0 & 13 & SC \\
PPK_2 & A & Flight 1 & V2000 & $<1 \mathrm{Km}$ & 0 & 13 & SC \\
PPK_3 & A & Flight 1 & V2000 & $<1 \mathrm{Km}$ & 1 & 12 & SC \\
PPK_4 & A & Flight 1 & V2000 & $<1 \mathrm{Km}$ & 3 & 10 & SC \\
PPK_5 & A + B & Flight 1 & V2000 & $<1 \mathrm{Km}$ & 1 & 12 & SC \\
PPK_6 & A + B & Flight 1 & V2000 & $<1 \mathrm{Km}$ & 3 & 10 & SC \\
PPK_7 & A & Flight 1 & V2000 & $<1 \mathrm{Km}$ & 0 & 13 & PC_1 \\
PPK_8 & A & Flight 1 & V2000 & $<1 \mathrm{Km}$ & 0 & 13 & PC_2 \\
PPK_9 & A + B & Flight 1 & V_RINEX & $<1 \mathrm{Km}$ & 0 & 13 & SC \\
PPK_10 & A + B & Flight 1 & CORS & $\approx 8 \mathrm{Km}$ & 0 & 13 & SC \\
PPK_11 & A + B & Flight 1 & CORS & $\approx 28 \mathrm{Km}$ & 0 & 13 & SC \\
PPK_12 & A + B & Flight 1 & CORS & $\approx 38 \mathrm{Km}$ & 0 & 13 & SC \\
PPK_13 & A + B & Flight 1 & CORS & $\approx 58 \mathrm{Km}$ & 0 & 13 & SC \\
PPK_14 & A + B & Flight 1 & CORS & $\approx 68 \mathrm{Km}$ & 0 & 13 & SC \\
PPK_15 & A + B & Flight 1 & CORS & $\approx 80 \mathrm{Km}$ & 0 & 13 & SC \\
\hline
\end{tabular}

${ }^{1}$ A refers to nadiral acquisitions, $\mathrm{B}$ to oblique ones. ${ }^{2} \mathrm{SC}=$ Self-Calibration. PC_1 refers to Caluso Calibration and PC_2 to on-the-job calibration at the surveyed area.

As is possible to see in the table, for Flight 1 , both nadiral images alone and nadiral and oblique images configurations were considered. In the configurations from PPK_1 to PPK_6, three different georeferencing strategies using a self-calibration approach were implemented and evaluated: the direct georeferencing approach without the use of GCPs, the direct georeferencing approach aided by one GCP, and the direct georeferencing approach aided by three GCPs (these last two cases can be referred to as mixed approaches).

The PPK_7 and PPK_8 configuration exploit the possibility of using an a priori estimated set of IOP derived by previously achieved self-calibration; the idea behind these tests was to enhance the direct georeferencing of the image block using a calibration certificate instead of one or more GCPs.

Several tests were also conducted using different data sources as the base station. Configurations from PPK_1 to PPK_8 used the data acquired in the field by a third part GNNS receiver (Geomax Zenith 35, positioned on the reference network vertex V2000) during the UAV flights. Configuration PPK_9 was processed using the data of a Virtual RINEX created ad-hoc (through the service of the SPINGNSS network) in the center of the area imaged during the flights. Finally, the configurations from PPK_10 to PPK_15 were adopted to assess the use of CORS observations, depending on the distance between the surveyed area and the CORS location.

\subsubsection{Real Time Kinematik (RTK): Network Real Time Kinematik (NRTK) and DJI-Real Time} Kinematik (DRTK)

In general terms, RTK approaches are more straightforward when compared with PPK, mainly because the camera positions are already computed with a higher accuracy during the flight, thanks to the corrections provided by a reference station. The Phantom 4 RTK also takes into account the offsets between APC and camera center during the acquisition phase and the geotagged coordinates are already corrected accordingly. Two different RTK approaches were tested: NRTK and DRTK.

For the NRTK approach, the SPIN3 GNSS network service was used by means of a connection between the UAV platform and the radio controller (an internet connection is also required). A virtual reference station was automatically created from the DJI application in the proximity of the area of interest. 
For the DRTK approach, the corrections were provided by the D-RTK 2 GNSS receiver that was placed on a reference network vertex whose coordinates were previously measured with traditional topographic techniques. The coordinates of the vertex were then set in the DJI Pilot app. The geotag of the acquired images were then directly corrected in the field thanks to the corrections provided by the D-RTK2 station. The processing of the RTK data collected during Flight 2 and Flight 3 was carried out following different strategies, as reported in Table 9.

Table 9. RTK processing strategies for Flight 2 (NRTK) and Flight 3 (DRTK).

\begin{tabular}{cccccc}
\hline ID & Flight Plan $^{\mathbf{1}}$ & Flight ID & No. of GCPs & No. of CPs & Camera Calibration $^{\mathbf{2}}$ \\
\hline NRTK_1 & A + B & Flight 2 & 0 & 13 & SC \\
NRTK_2 & A & Flight 2 & 0 & 13 & SC \\
NRTK_3 & A + B & Flight 2 & 1 & 12 & SC \\
NRTK_4 & A & Flight 2 & 1 & 12 & SC \\
NRTK_5 & A + B & Flight 2 & 3 & 10 & SC \\
NRTK_6 & A & Flight 2 & 3 & 10 & SC \\
DRTK_1 & A + B & Flight 3 & 0 & 13 & SC \\
DRTK_2 & A & Flight 3 & 0 & 13 & SC \\
DRTK_3 & A + B & Flight 3 & 1 & 12 & SC \\
DRTK_4 & A & Flight 3 & 1 & 12 & SC \\
DRTK_5 & A + B & Flight 3 & 3 & 10 & SC \\
DRTK_6 & A & Flight 3 & 3 & 10 & SC \\
\hline
\end{tabular}

${ }^{1} \mathrm{~A}$ refers to nadiral acquisitions, B to oblique ones. ${ }^{2} \mathrm{SC}$ refers to Self-Calibration.

As for the PPK as well as for all the RTK data, both nadiral images alone and nadiral and oblique image configurations were considered. Furthermore, also for this approach, the strategy of enhancing the direct georeferencing with one or more GCPs was tested and analyzed. Finally, only the self-calibration approach for the IOP estimation was adopted. This decision was made based on the results of the tests carried out in a previous work [65] and confirmed by the results of the PPK approach (also to limit the number of tables and graphs of the manuscript).

\section{Results}

In this section, the results obtained exploiting the different configurations for the direct georeferencing of the photogrammetric block will be reported. The main parameter considered to assess the accuracy of the different solutions is the RMSE on the control points used as CPs in the photogrammetric processing.

$$
\begin{gathered}
\text { RMSe }_{\mathrm{X}}=\sqrt{\frac{\sum_{i=1}^{n} \Delta x_{i}^{2}}{n}} R M S e_{y}=\sqrt{\frac{\sum_{i=1}^{n} \Delta y_{i}^{2}}{n}} R_{M S e_{z}}=\sqrt{\frac{\sum_{i=1}^{n} \Delta z_{i}^{2}}{n}} \\
\text { RMSe }_{\mathrm{TOT}}=\sqrt{R^{2} S e_{x}{ }^{2}+R M S e_{y}{ }^{2}+R M S e_{z}{ }^{2}}
\end{gathered}
$$

where $\Delta x_{i}, \Delta y_{i}$, and $\Delta z_{i}$ are the differences between the measured 3D coordinates and the coordinates calculated through the photogrammetric approach and $n$ is the number of GCPs or CPs considered.

The RMSE allowed us to identify which configurations produced the best results in terms of positional accuracy, investigating possible bias in the $x, y$, and $z$ components, and can be used to assess the nominal map scale of the added-value photogrammetric products (e.g., orthoimagery).

\section{1. $P P K$}

The results of the PPK approach will be described in two separated blocks: (i) from PPK_1 to PPK_9 where the base station used for the PPK processing is located in the surveyed area (both physically or virtually), and (ii) from PPK_10 to PPK_15 where the data derived from CORSs located at different distances from the area were used as the base station. In Table 10, the RMSE on CPs is shown 
for the different configurations: the error for $x, y$, and $z$ components as well as the total error (see aforementioned formulas) are reported. In Figure 4, the RMSE ${ }_{\mathrm{TOT}}$ on CPs is represented for PPK_1, PPK_3, PPK_6, and PPK_9. PPK2 (direct georeferencing is not included in Figure 4 since the related RMSE $_{\mathrm{TOT}}$ value is characterized by a different order of magnitude, i.e., $>3 \mathrm{~m}$ ).

Table 10. PPK approach. RMSE on CPs for configuration from PPK_1 to PPK_9.

\begin{tabular}{|c|c|c|c|c|c|c|c|c|}
\hline ID & Flight Plan ${ }^{1}$ & RMSEE X(m) & RMSE Y (m) & RMSE Z (m) & RMSE TOT (m) & No. of GCPs & No. of CPs & Camera Calibration $^{2}$ \\
\hline PPK_1 & $A+B$ & 0.012 & 0.009 & 0.028 & 0.032 & 0 & 13 & SC \\
\hline PPK_2 & A & 0.319 & 0.296 & 2.988 & 3.019 & 0 & 13 & SC \\
\hline PPK_3 & A & 0.197 & 0.169 & 0.280 & 0.382 & 1 & 12 & SC \\
\hline PPK_4 & A & 0.012 & 0.009 & 0.142 & 0.143 & 3 & 10 & SC \\
\hline PPK_5 & $A+B$ & 0.006 & 0.009 & 0.032 & 0.034 & 1 & 12 & SC \\
\hline PPK_6 & $A+B$ & 0.007 & 0.009 & 0.019 & 0.022 & 3 & 10 & $\mathrm{SC}$ \\
\hline PPK_7 & A & 0.114 & 0.113 & 0.117 & 0.199 & 0 & 13 & PC_1 \\
\hline PPK_8 & A & 0.081 & 0.076 & 0.118 & 0.162 & 0 & 13 & PC_2 \\
\hline PPK_9 & $A+B$ & 0.012 & 0.014 & 0.025 & 0.031 & 0 & 13 & $\mathrm{SC}$ \\
\hline
\end{tabular}

${ }^{1}$ A refers to nadiral acquisitions, B to oblique ones. ${ }^{2}$ SC refers to Self-Calibration. PC_1 refers to Caluso Calibration and PC_2 to on the job calibration at Venaria.

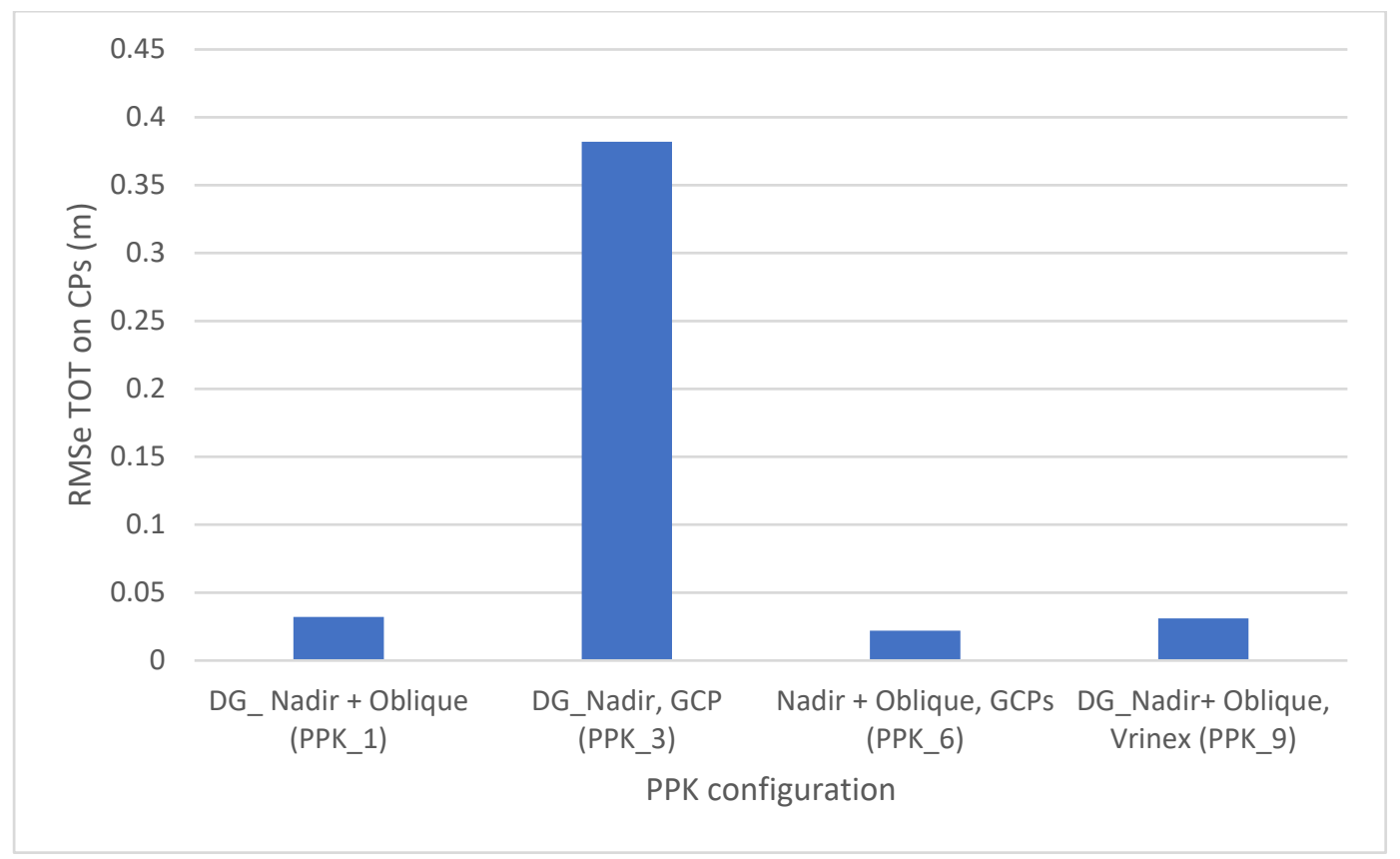

Figure 4. RMSE $\mathrm{TOT}_{\mathrm{T}}$ on CPs for different PPK configurations (PPK_1, PPK_3, PPK_6, and PPK_9).

The last column of the table reports the strategy adopted for the IOP estimation: for the major part of the solutions, self-calibration was chosen while PPK_7 and PPK_8 were processed using two different calibration certificates. For PPK_7, self-calibration obtained some months before the acquisition in the same area was used. This self-calibration was obtained using only nadiral images, 11 GCPs, and a flight height of $40 \mathrm{~m}$ (the specifications of this calibration are reported in [66]). For PPK_8, a different strategy was tested, employing an on-the job calibration based on both nadiral and oblique acquisitions of Flight 1, but for the photogrammetric processing, only nadiral acquisition was used since it was the most challenging configuration for a direct georeferencing approach.

All the different configurations were processed using as the base station the data derived from the Geomax receiver placed on V2000, except for PPK_9, which used as the base station an ad hoc created Virtual RINEX.

Observing the RMSE for the configuration from PPK_1 to PPK_6, it can be underlined that the integration of oblique images plays a crucial role in obtaining a lower RMSE on CPs, allowing centimeter accuracies to be achieved without any GCPs. In general terms, it is clear, as expected, that the use of a dataset composed only of nadiral images can encounter some issues during the processing, with the 
accuracies in the range of meters. As a matter of fact, the use of only nadiral images without adopting any GCPs can lead to a weak geometry of the acquisition for IOP estimation with an inaccurate estimation of the camera calibration parameters, especially for the focal length component, leading to a bias in the $z$ component of the CP RMSE.

The first solution adopted to reduce the impact of this element foresee the use of GCPs following two different strategies: a single GCP placed in the center of the area or three GCPs (one in the center and two at the borders of the area). The impact of this solution is clearly shown in PPK_3 and PPK_4 where only nadiral images were used. The use of one GCP in PPK_3 improved the RMSE from around $3 \mathrm{~m}$ to $0.3 \mathrm{~m}$, while using three GCPs, as in PPK_4, it is possible to further improve the RMSE to $0.15 \mathrm{~m}$.

The impact of GCPs is less evident when oblique images are integrated with nadiral images during the processing, as expected. One GCP alone, like in the PPK_5 configuration, has no impact in the RMSE on CPs, while using three GCPs led to a slight reduction of the error of the RMSE to 0.02 m (PPK_6).

The main cause of the issue underlined for the first PPK configurations examined was thus connected with the IOP estimation, as reported in Table 11. If we compare the parameters estimated for PPK_1 with the ones estimated for the nadiral flights (PPK_2, PPK_3, and PPK_4), it is possible to notice how the focal length $f$ is the most variable parameters in these tests. The use of one or three GCPs produced results similar to the IOP estimation based on the integration of oblique images and comparable with both self-calibration PC_1 and PC_2, as reported in Table 7. On the other hand, the no GCP and nadiral only configuration resulted in one that estimated the focal length parameter with the worst accuracy. The fact that the three GCP configuration was less accurate when compared with the one GCP could be caused by the flight configuration and the distribution of the selected GCPs across the scene.

Table 11. IOP estimated through the self-calibration approach for different PPK configurations.

\begin{tabular}{ccccc}
\hline IOP & PPK_1 & PPK_2 (no GCPs) & PPK_3 (1 GCP) & PPK_4 (3 GCPs) \\
\hline $\mathbf{f}$ & 3627.483 & 3417.831 & 3609.374 & 3592.392 \\
$\mathbf{k} 1$ & -0.266 & -0.233 & -0.261 & -0.260 \\
$\mathbf{k} 2$ & 0.108 & 0.084 & 0.105 & 0.104 \\
k3 & -0.031 & -0.021 & -0.030 & -0.029 \\
$\mathbf{k}$ 4 & 0.000 & 0.000 & 0.000 & 0.000 \\
$\mathbf{c x}$ & -4.449 & -12.515 & -11.837 & -11.893 \\
$\mathbf{c y}$ & 6.310 & 3.260 & 4.827 & 4.694 \\
$\mathbf{p} 1$ & -0.001 & 0.000 & 0.000 & 0.000 \\
$\mathbf{p} 2$ & 0.000 & 0.000 & 0.000 & 0.000 \\
b1 & -0.110 & 0.029 & 0.070 & 0.065 \\
$\mathbf{b} 2$ & -0.035 & 0.299 & 0.346 & 0.329 \\
\hline
\end{tabular}

Another strategy that can be adopted to deal with the issues caused using only nadiral images is the one that uses a calibration certificate already available. Two different tests were performed: PPK_7 and PPK_8. For PPK_7, the use of a calibration certificate obtained during a previous experience at the Castellazzo di Caluso (PC_1) allowed us to reduce the RMSE $\mathrm{TOT}_{\text {TOT }}$ of the nadiral only dataset without GCPs from $3 \mathrm{~m}$ (PPK_2) to $0.2 \mathrm{~m}$.

In the case of PPK_8, the calibration certificate PC_2 was obtained adopting an on-the-job self-calibration at Venaria. Despite this calibration being calculated using both nadiral and oblique images, the accuracy for PPK_8 was only slightly better than PPK_7 (0.16 m for PPK_8 and $0.2 \mathrm{~m}$ for PPK_7). The results of these two configurations demonstrate once again how crucial the phase of camera calibration is and how oblique images can positively impact this phase of photogrammetric processing.

Finally, PPK_9, which was processed integrating nadiral and oblique images and using a Virtual RINEX as the base station, was characterized by an RMSE ${ }_{T O T}$ equal to the one of PPK_1 that was processed with the data retrieved from the Geomax Zenith 35 as the base station. This result 
demonstrates that using a Virtual RINEX (extrapolated from the data of different CORSs), it is possible to achieve the same level of accuracy of a configuration exploiting a GNSS receiver in the field. If a reliable network of permanent GNSS stations is available, it is therefore possible to skip the positioning of a GNSS master station in the field, speeding up the acquisition phase and without the need to use an additional GNSS receiver.

The second block of results is reported in Table 12, related to the configurations (from PPK_10 to PPK_15) where the base station used for PPK computation was derived from the CORSs of SPIN3 GNSS. The idea behind these tests was to evaluate how the distance between the CORS and the surveyed area can affect the positional accuracy of the photogrammetric block orientation. The selected CORS are characterized by a distance from the test area in the range from $8 \mathrm{~km}$ to $80 \mathrm{~km}$.

Table 12. PPK approach. RMSE on CPs for configuration from PPK_10 to PPK_15.

\begin{tabular}{cccccccc}
\hline ID & Flight Plan ${ }^{1}$ & RMSE $\mathbf{~}(\mathbf{m})$ & RMSE $\mathbf{~ ( m ) ~}$ & RMSE Z $(\mathbf{m})$ & RMSE TOT $(\mathbf{m})$ & Base Station & Base Station Distance \\
\hline PPK_10 & A + B & 0.010 & 0.026 & 0.021 & 0.035 & CORS_TORINO & $\approx 8$ Km \\
PPK_11 & A + B & 0.017 & 0.012 & 0.032 & 0.038 & CORS_CUORGNE' & CORS \\
PPK_12 & A + B & 0.023 & 0.025 & 0.079 & 0.086 & CRESCENTINO & $\approx 38$ Km \\
PPK_13 & A + B & 0.015 & 0.012 & 0.097 & 0.098 & CORS_BIELLA & $\approx 58$ Km \\
PPK_14 & A + B & 0.013 & 0.020 & 0.156 & 0.158 & CORS_CANELLI & $\approx 68$ Km \\
PPK_15 & A + B & 0.029 & 0.023 & 0.184 & 0.188 & CORS_ALESSANDRIA & $\approx 80$ Km \\
\hline \multicolumn{7}{r}{ A refers to the nadiral acquisition, B to the oblique. }
\end{tabular}

For the accuracy assessment of these configurations, the same number of CPs (13) was used. In Figure 5, the RMSE on CPs was sorted with respect to the distance from the site, from the closest to the farthest CORS. As expected, the distance from the acquisition area directly impacted the RMSE value, especially in the elevation component. It has to be highlighted that the accuracy of the planimetric component was a few centimeters, even up to $80 \mathrm{~km}$, from the area of the acquisition, while good accuracy for the altimetric component could be achieved in the range of $30 \mathrm{~km}$. It is crucial, however, to analyze these results taking the nominal map scale of the survey into account. For example, the accuracy of PPK_15 (around $0.2 \mathrm{~m}$ ) can still be sufficient to guarantee a nominal map scale of 1:1000, even with a CORS distance of about $80 \mathrm{~km}$.

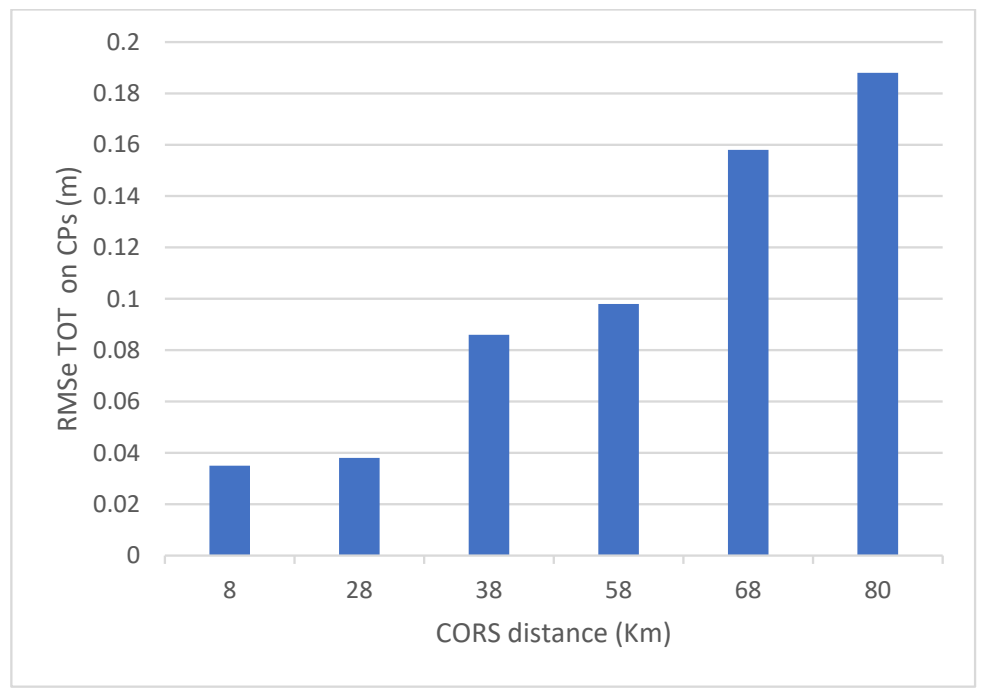

Figure 5. RMSE $\mathrm{TOT}_{\text {T }}$ of CPs for configuration from PPK_10 to PPK_15.

\subsection{NRTK}

The RMSE for the NRTK configuration is shown in Table 13. Six different solutions were tested, depending on the type of images acquired in the field (nadiral and oblique) and the number of GCPs used for the block orientation (0, 1, and 3). For all solutions, a self-calibration approach was adopted. 
Table 13. (N)RTK approach. RMSE on CPs for configuration from NRTK_1 to NRTK_6.

\begin{tabular}{|c|c|c|c|c|c|c|c|}
\hline ID & Flight Plan ${ }^{1}$ & $\operatorname{RMSE} X(\mathrm{~m})$ & RMSE Y (m) & RMSE Z (m) & RMSE TOT (m) & No. of GCPs & No. of CPs \\
\hline NRTK_1 & $A+B$ & 0.011 & 0.009 & 0.040 & 0.042 & 0 & 13 \\
\hline NRTK_2 & A & 0.026 & 0.016 & 0.418 & 0.419 & 0 & 13 \\
\hline NRTK_3 & $A+B$ & 0.014 & 0.010 & 0.034 & 0.038 & 1 & 12 \\
\hline NRTK_4 & $\mathrm{A}$ & 0.020 & 0.012 & 0.021 & 0.031 & 1 & 12 \\
\hline NRTK_5 & $A+B$ & 0.007 & 0.008 & 0.029 & 0.031 & 3 & 10 \\
\hline NRTK_6 & A & 0.016 & 0.010 & 0.022 & 0.029 & 3 & 10 \\
\hline
\end{tabular}

${ }^{1}$ a refers to nadiral acquisitions, $\mathrm{b}$ to oblique ones.

The RMSE $\mathrm{TOT}_{\mathrm{TO}}$ on CPs for different NRTK configurations (NRTK_1, NRTK_2 and NRTK_5) is shown in Figure 6.

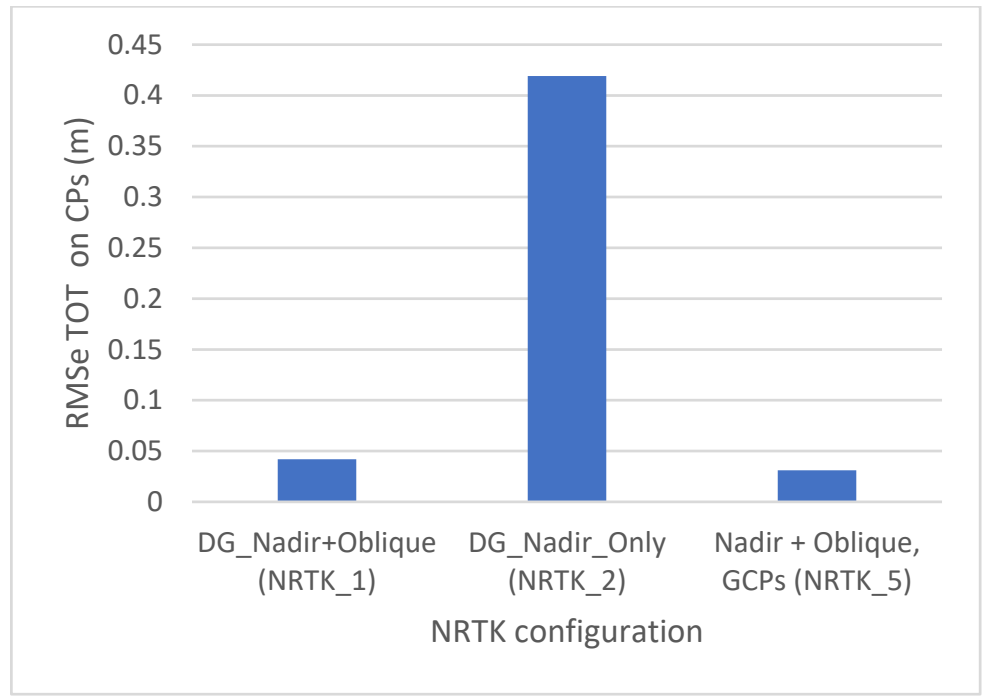

Figure 6. RMSE $\mathrm{TOT}_{\mathrm{T}}$ of $\mathrm{CPs}$ for different NRTK configurations (NRTK_1, NRTK_2, and NRTK_5).

All six configurations were characterized by a low RMSE on the CPs: the only exception was represented by the NRTK_2 configuration, which only used nadiral images and was processed without any GCPs. This configuration led to a RMSE of $0.42 \mathrm{~m}$, with a clear bias in the $\mathrm{z}$ component. As for the PPK processing, this error was related to the wrong estimation of the IOP. It is worth mentioning that the use of one single GCP is sufficient to reduce the RMSE to $0.03 \mathrm{~m}$ as demonstrated by the results of the NRTK_4 test. The use of more than one GCP did not impact the accuracy of the block orientation significantly. Compared to the PPK processing, the impact of oblique images was less significant, as confirmed also in [65]. The NRTK nadiral only dataset performed better than the PPK nadiral only dataset. This is probably related to a better estimation of the camera positions during the flight: nevertheless, further tests are required to investigate this hypothesis.

This behavior was also confirmed by the DRTK tests and can be related to the changing of environmental conditions during the acquisition of the three datasets. Flight 1 was performed with homogenous lighting of the scene due to the presence of cloud, while for Flights 2 and 3 , the light conditions were more unstable. Moreover, Flights 2 and 3 were also influenced by the presence of wind gusts. These two environmental factors affected the quality of the acquired images and thus the phases of image matching and feature extractions, especially for oblique images.

\subsection{DRTK}

For the processing of the different DRTK solutions (from DRTK_1 to DRTK_6), we adopted the same strategy already used for the NRTK approach. The different DRTK processing strategies are summarized in Table 14. 
Table 14. DRTK approach. RMSE on CPs for configuration from NRTK_1 to NRTK_6.

\begin{tabular}{cccccccc}
\hline ID & Flight Plan ${ }^{1}$ & RMSE X (m) & RMSE Y (m) & RMSE Z (m) & RMSE TOT (m) & No. of GCPs & No. of CPs \\
\hline DRTK_1 & A + B & 0.027 & 0.037 & 0.049 & 0.067 & 0 \\
DRTK_2 & A & 0.030 & 0.036 & 0.446 & 0.449 & 0 \\
DRTK_3 & A + B & 0.022 & 0.032 & 0.045 & 0.060 & 13 \\
DRTK_4 & A & 0.032 & 0.035 & 0.033 & 0.057 & 13 \\
DRTK_5 & A + B & 0.038 & 0.023 & 0.050 & 0.066 & 3 \\
DRTK_6 & A & 0.021 & 0.025 & 0.024 & 0.040 & 12 \\
\hline
\end{tabular}

${ }^{1}$ A refers to the nadiral acquisition, $\mathrm{B}$ to the oblique.

The RMSE $\mathrm{TOT}_{\mathrm{TO}}$ on CPs for different DRTK configurations (DRTK_1, DRTK_2 and DRTK_5) is shown in Figure 7.

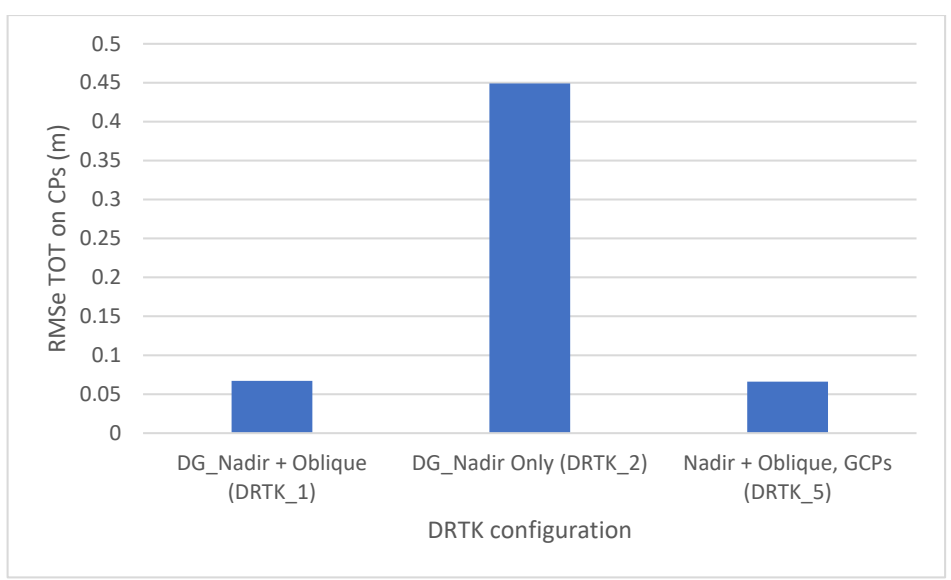

Figure 7. RMSE $\mathrm{TOT}_{\mathrm{T}}$ of CPs for different DRTK configurations (DRTK_1, DRTK_2, and DRTK_5).

The RMSE of the DRTK approach was comparable (slightly higher) with the NRTK results and is affected by the same bias. Additionally, in this case, the configuration with only nadiral images and without GCPs (DRTK_2) was the one affected by the higher RMSE value, while all the other configurations presented similar errors. No significant differences can be reported between the use of one or more GCPs. For the reasons already reported in the previous section, the impact of oblique images was also limited in this case.

A summary of the results achieved adopting the different direct georeferencing solutions is reported in Table 15 as well as the best solution that combines direct georeferencing and the use of a few GCPs (PPK 6).

Table 15. Summary of the results of the different direct georeferencing approaches tested and the best mixed solution (one GCP only).

\begin{tabular}{ccccc}
\hline ID & Georef. Approach & Flight Plan & RMSE TOT on CPs & No. of GCPs/CPs \\
\hline PPK_1 & Direct Georef. & Nadiral + Oblique & 0.032 & $0 / 13$ \\
PPK_2 & Direct Georef. & Nadiral & 3.019 & $0 / 13$ \\
PPK_9 & Direct Georef. & Nadiral + Oblique & 0.031 & $0 / 13$ \\
PPK_10 & Direct Georef. & Nadiral + Oblique & 0.035 & $0 / 13$ \\
NRTK_1 & Direct Georef. & Nadiral + Oblique & 0.042 & $0 / 13$ \\
NRTK_2 & Direct Georef. & Nadiral & 0.419 & $0 / 13$ \\
DRTK_1 & Direct Georef. & Nadiral + Oblique & 0.067 & $0 / 13$ \\
DRTK_2 & Direct Georef. & Nadiral & 0.449 & $0 / 13$ \\
PPK_6 & Direct Georef. + GCPs & Nadiral + Oblique & 0.022 & $3 / 10$ \\
\hline
\end{tabular}

\section{Discussion and Conclusions}

The results reported in the previous sections demonstrates that the 3D positional accuracy of UAV photogrammetric models generated by means of a direct georeferencing approach is below $5 \mathrm{~cm}$ when the flight and acquisition parameters meet specific criteria. More specifically, the best-case scenario 
was characterized by a 3D accuracy of $3 \mathrm{~cm}$, fitting the Italian mapping standard of a 1:100 nominal map scale (i.e., very large map scale mapping). This is also in line with the accuracy stated by DJI for the multirotor platform Phantom 4 RTK, which was used for the tests presented in this manuscript (i.e., an horizontal accuracy of the generated photogrammetric models of $5 \mathrm{~cm}$ at $100 \mathrm{~m}$ flight height and with good illumination conditions). Nevertheless, to adopt the best solution for a direct georeferencing approach, specific guidelines need to be followed. The analysis of the results presented in the previous sections allowed the authors to develop and propose specific best practices for UAV-based 3D mapping with a direct georeferencing approach. As far as the flight planning is concerned, the inclusion of oblique images is strongly recommended since it strengthens the acquisition geometry enhancing the IOP estimation. All tests clearly demonstrated that the use of nadiral images only led to bias in the RMSE on the elevation component during the block orientation phase. When oblique images are not available, this issue can be mitigated using a single GCP; this approach has been tested with artificial targets, however, it can also be pursued using natural features whose coordinates can be extracted from already available orthoimagery (with suitable accuracy) covering the area of interest. Otherwise, an a priori camera calibration can also be exploited, leading to slightly lower accuracies.

In general terms, the PPK approach led to the best 3D accuracy of the block orientation phase without the use of GCPs. The effectiveness of this approach was tested by adopting different types of GNSS base stations. All GNSS observations acquired in the field, data derived from CORSs, and virtual GNSS stations were proven to be feasible solutions. The possibility of using data derived from a permanent network of geodetic stations enables a faster acquisition in the field as well as lower requirements in terms of instrumentation to be deployed. It has to be highlighted that the use of a Virtual RINEX leads to the same accuracy of a PPK approach based on a GNSS master station positioned in the field. If a virtual reference station service is not available, observation from a single CORS can also be employed, but, depending on the positional accuracies requirements, the distance between the station and the site must be carefully considered. For large map scale mapping purposes, we strongly suggest using a CORS station in the range of $30 \mathrm{~km}$ from the surveyed area.

As far as the RTK solution is concerned, the approaches presented in this manuscript were based on two different strategies: a NRTK solution and a RTK one, both leading to slightly lower accuracy when compared with PPK (but still better than $0.07 \mathrm{~m}$ ). Nevertheless, RTK solutions positively impact the timeliness of both data acquisition and data processing phases.

The NRTK requires the availability of a network of CORSs and a NTRIP service: a stable mobile network is therefore needed to receive the RTK corrections in real time. When one or more of these conditions cannot be fulfilled, it is possible to adopt a RTK approach. The DJI solution called DRTK was tested by using the D-RTK 2 GNSS receiver set on a point of known coordinates, allowing us to reach a higher accuracy with respect to the positioning on an unknown point.

The aforementioned best practices are summarized in the flowchart shown in Figure 8, based also on a cost-benefit analysis. In the lower part of the image, some categorizations of the different approaches based on different elements are also reported.

The first element that needs to be considered is the actual need of a RTK approach, which should take several factors into account, mainly in terms of environmental conditions of the area (accessibility, safety of the operators), available resources (human and economic), time constraints and, obviously, 3D mapping accuracy requirements.

A crucial role in the choice of the solution to be adopted is also played by the experience of the operator. The PPK approach requires a specific expertise in processing the GNSS raw observations (no specific user-friendly processing software is currently available). NRTK requires the lowest effort from the operator perspective as well as in terms of instruments to be deployed in the field. The (D)RTK implies additional efforts (positioning of a GNSS master station) during acquisition in the field, while its processing is faster than PPK. 


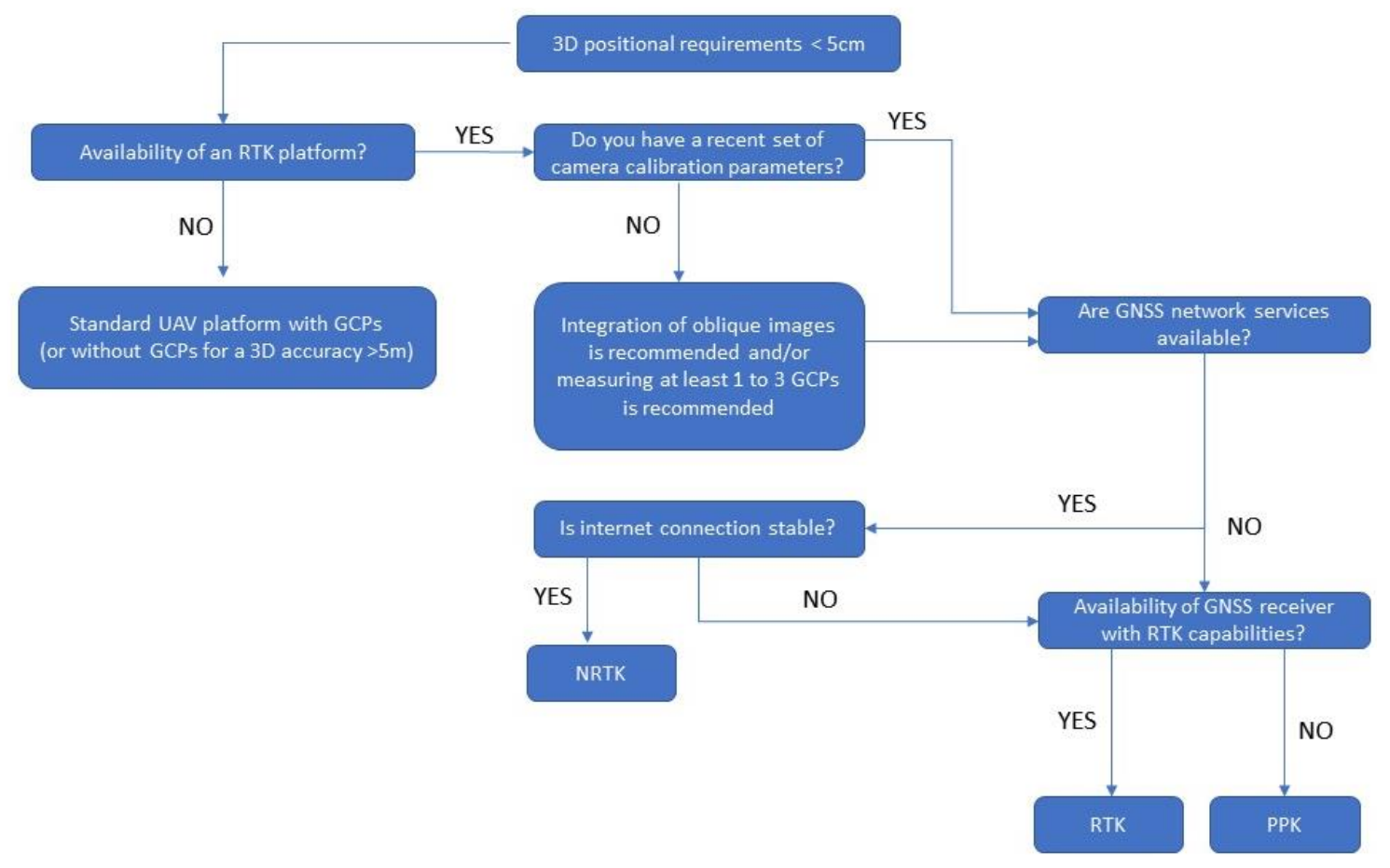

Best solution in terms of timeliness (lowest to highest)

$>P P K>D R T K \sum N R T$

Best solution in terms of needed expertise (lowest to highest)

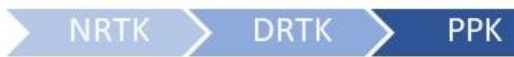

Figure 8. Flowchart summarizing the best operational approaches depending on the map accuracy requirements and available technological solutions.

According to the presented results, it is possible to outline further research topics related to direct georeferencing that could be investigated in the near future. General automatization of the process, ranging from the acquisition phase to the data processing, is still needed and the amount of expertise required to adopt these approaches is still high. Different strategies can be followed to further optimize both the acquisition and processing phase. Camera calibration also plays a crucial role in the phase of EO (Exterior Orientation) and the accuracy of the solution that adopts a pre-calibrated IOP is still under evaluation and needs further testing.

An additional assessment of the accuracy of direct georeferencing could be based on the assessment of the positional accuracy of camera positions in addition to the accuracy on CP (e.g., tracking the UAVs trajectory by traditional topographic techniques and a prism mounted on the platform, as proposed in [73]. The platform tracking would also allow the actual flight path to be checked with respect to the designed flight plan, which could be a critical issue in areas with obstacles and occlusions.

Author Contributions: The overall methodological approach of the paper and the experimental framework were defined together by the three authors: Lorenzo Teppati Losè, Filiberto Chiabrando and Fabio Giulio Tonolo as well as the acquisition phase in the field. The processing and the development of the experimental setup was developed by Lorenzo Teppati Losè as well as the writing of the draft. The manuscript was then revised and edited by all three authors together. Conceptualization, Lorenzo Teppati Losè, Filiberto Chiabrando and Fabio Giulio Tonolo; Methodology, Lorenzo Teppati Losè, Filiberto Chiabrando and Fabio Giulio Tonolo; Supervision, Filiberto Chiabrando and Fabio Giulio Tonolo; Validation, Lorenzo Teppati Losè, Filiberto Chiabrando and Fabio Giulio Tonolo; Writing-original draft, Lorenzo Teppati Losè; Writing_-review \& editing, Filiberto Chiabrando and Fabio Giulio Tonolo. All authors have read and agreed to the published version of the manuscript. 
Funding: This research received no external funding.

Acknowledgments: The authors would like to thank the direction of the Reggia di Venaria for allowing the realization of the experimental tests in the field and the Laboratory of Geomatics of the DIATI Department of Politecnico of Turin, and in particular Andrea Lingua and Paolo Maschio for their support in the use of the platform in the field campaign.

Conflicts of Interest: The authors declare no conflict of interest.

\section{References}

1. Colomina, I.; Molina, P. Unmanned aerial systems for photogrammetry and remote sensing: A review. ISPRS J. Photogramm. Remote Sens. 2014, 92, 79-97. [CrossRef]

2. Nex, F.; Remondino, F. UAV for 3D mapping applications: A review. Appl. Geomat. 2014, 6, 1-15. [CrossRef]

3. Deng, L.; Mao, Z.; Li, X.; Hu, Z.; Duan, F.; Yan, Y. UAV-based multispectral remote sensing for precision agriculture: A comparison between different cameras. ISPRS J. Photogramm. Remote Sens. 2018, 146, 124-136. [CrossRef]

4. Maes, W.H.; Steppe, K. Perspectives for Remote Sensing with Unmanned Aerial Vehicles in Precision Agriculture. Trends Plant Sci. 2019, 24, 152-164. [CrossRef]

5. Zheng, H.; Cheng, T.; Zhou, M.; Li, D.; Yao, X.; Tian, Y.; Cao, W.; Zhu, Y. Improved estimation of rice aboveground biomass combining textural and spectral analysis of UAV imagery. Precis. Agric. 2019, 20, 611-629. [CrossRef]

6. Comba, L.; Biglia, A.; Aimonino, D.R.; Gay, P. Unsupervised detection of vineyards by 3D point-cloud UAV photogrammetry for precision agriculture. Comput. Electron. Agric. 2018, 155, 84-95. [CrossRef]

7. Aicardi, I.; Nex, F.; Gerke, M.; Lingua, A. An Image-Based Approach for the Co-Registration of Multi-Temporal UAV Image Datasets. Remote Sens. 2016, 8, 779. [CrossRef]

8. Thiel, C.; Schmullius, C. Comparison of UAV photograph-based and airborne lidar-based point clouds over forest from a forestry application perspective. Int. J. Remote Sens. 2017, 38, 2411-2426. [CrossRef]

9. Hassaan, O.; Nasir, A.K.; Roth, H.; Khan, M.F. Precision Forestry: Trees Counting in Urban Areas Using Visible Imagery based on an Unmanned Aerial Vehicle. IFAC-PapersOnLine 2016, 49, 16-21. [CrossRef]

10. Grznárová, A.; Mokroš, M.; Surový, P.; Slavík, M.; Pondelík, M.; Merganič, J. The Crown Diameter Estimation from Fixed Wing Type of Uav Imagery. Int. Arch. Photogramm. Remote Sens. Spat. Inf. Sci. 2019. [CrossRef]

11. Campana, S. Drones in Archaeology. State-of-the-Art and Future Perspectives. Archaeol. Prospect. 2017, 24, 275-296. [CrossRef]

12. Stek, T.D. Drones over Mediterranean landscapes. The potential of small UAV's (drones) for site detection and heritage management in archaeological survey projects: A case study from Le Pianelle in the Tappino Valley, Molise (Italy). J. Cult. Herit. 2016, 22, 1066-1071. [CrossRef]

13. Georgopoulos, A.; Oikonomou, C.; Adamopoulos, E.; Stathopoulou, E.K. Evaluating unmanned aerial platforms for cultural heritage large scale mapping. ISPRS Int. Arch. Photogramm. Remote Sens. Spat. Inf. Sci. 2016, XLI-B5, 355-362. [CrossRef]

14. de Reu, J.; Trachet, J.; Laloo, P.; de Clercq, W. From Low Cost UAV Survey to High Resolution Topographic Data: Developing Our Understanding of a Medieval Outport of Bruges. Archaeol. Prospect. 2016, 23, 335-346. [CrossRef]

15. Adami, A.; Fregonese, L.; Gallo, M.; Helder, J.; Pepe, M.; Treccani, D. Ultra Light Uav Systems for the Metrical Documentation of Cultural Heritage: Applications for Architecture and Archaeology. ISPRS Int. Arch. Photogramm. Remote Sens. Spat. Inf. Sci. 2019, XLII-2/W17, 15-21. [CrossRef]

16. Murtiyoso, A.; Grussenmeyer, P.; Freville, T. Close range uav accurate recording and modeling of St-Pierre-Le-Jeune Neo-Romanesque church in Strasbourg (France). Int. Arch. Photogramm. Remote Sens. Spat. Inf. Sci. ISPRS Arch. 2017, 42, 519-526. [CrossRef]

17. Bolognesi, M.; Furini, A.; Russo, V.; Pellegrinelli, A.; Russo, P. Testing the low-cost rpas potential in 3D cultural heritage reconstruction. Int. Arch. Photogramm. Remote Sens. Spat. Inf. Sci. ISPRS Arch. 2015, 40, 229-235. [CrossRef]

18. Manfreda, S.; McCabe, M.F.; Miller, P.E.; Lucas, R.; Pajuelo Madrigal, V.; Mallinis, G.; Ben Dor, E.; Helman, D.; Estes, L.; Ciraolo, G.; et al. On the use of unmanned aerial systems for environmental monitoring. Remote Sens. 2018, 10, 641. [CrossRef] 
19. Toro, F.G.; Tsourdos, A. UAV Sensors for Environmental Monitoring; MDPI AG-Multidisciplinary Digital Publishing Institute: Basel, Switzerland, 2018.

20. Tripolitsiotis, A.; Prokas, N.; Kyritsis, S.; Dollas, A.; Papaefstathiou, I.; Partsinevelos, P. Dronesourcing: A modular, expandable multi-sensor UAV platform for combined, real-time environmental monitoring. Int. J. Remote Sens. 2017, 38, 2757-2770. [CrossRef]

21. Green, D.R.; Hagon, J.J.; Gómez, C.; Gregory, B.J. Using low-cost UAVs for environmental monitoring, mapping, and modelling: Examples from the coastal zone. In Coastal Management: Global Challenges and Innovations; Elsevier: Amsterdam, The Netherlands, 2018; pp. 465-501.

22. Gonçalves, G.R.; Pérez, J.A.; Duarte, J. Accuracy and effectiveness of low cost UASs and open source photogrammetric software for foredunes mapping. Int. J. Remote Sens. 2018, 39, 5059-5077. [CrossRef]

23. Duarte, D.; Nex, F.; Kerle, N.; Vosselman, G. Towards a more efficient detection of earthquake induced façade damages using oblique UAV imagery. Int. Arch. Photogramm. Remote Sens. Spat. Inf. Sci. ISPRS Arch. 2017, 42, 93-100. [CrossRef]

24. Boccardo, P.; Chiabrando, F.; Dutto, F.; Tonolo, F.; Lingua, A. UAV Deployment Exercise for Mapping Purposes: Evaluation of Emergency Response Applications. Sensors 2015, 15, 15717-15737. [CrossRef]

25. Sutheerakul, C.; Kronprasert, N.; Kaewmoracharoen, M.; Pichayapan, P. Application of Unmanned Aerial Vehicles to Pedestrian Traffic Monitoring and Management for Shopping Streets. Transp. Res. Procedia 2017, 25, 1717-1734. [CrossRef]

26. Ke, R.; Li, Z.; Tang, J.; Pan, Z.; Wang, Y. Real-Time Traffic Flow Parameter Estimation From UAV Video Based on Ensemble Classifier and Optical Flow. IEEE Trans. Intell. Transp. Syst. 2018, 20, 54-64. [CrossRef]

27. Ham, Y.; Han, K.K.; Lin, J.J.; Golparvar-Fard, M. Visual monitoring of civil infrastructure systems via camera-equipped Unmanned Aerial Vehicles (UAVs): A review of related works. Vis. Eng. 2016, 4, 1. [CrossRef]

28. Morgenthal, G.; Hallermann, N. Quality Assessment of Unmanned Aerial Vehicle (UAV) Based Visual Inspection of Structures. Adv. Struct. Eng. 2016, 17, 289-302. [CrossRef]

29. Carbonneau, P.E.; Dietrich, J.T. Cost-effective non-metric photogrammetry from consumer-grade sUAS: Implications for direct georeferencing of structure from motion photogrammetry. Earth Surf. Process. Landf. 2017, 42, 473-486. [CrossRef]

30. Giones, F.; Brem, A. From toys to tools: The co-evolution of technological and entrepreneurial developments in the drone industry. Bus. Horiz. 2017, 60, 875-884. [CrossRef]

31. Stöcker, C.; Bennett, R.; Nex, F.; Gerke, M.; Zevenbergen, J. Review of the current state of UAV regulations. Remote Sens. 2017, 9, 459. [CrossRef]

32. Regolamento, E.N. Mezzi Aerei A Pilotaggio Remoto, Edizione 3 del 11 novembre 2019.2019. Available online: https://www.enac.gov.it/news/regolamento-mezzi-aerei-pilotaggio-remoto-ed-3-dell11novembre-2019 (accessed on 30 September 2020).

33. Peppa, M.V.; Hall, J.; Goodyear, J.; Mills, J.P. Photogrammetric assessment and comparison of dji phantom 4 pro and phantom 4 rtk small unmanned aircraft systems. Int. Arch. Photogramm. Remote Sens. Spat. Inf. Sci. ISPRS Arch. 2019, 42, 503-509. [CrossRef]

34. Palanirajan, H.K.; Alsadik, B.; Nex, F.; Elberink, S.O. Efficient flight planning for building façade 3D reconstruction. Int. Arch. Photogramm. Remote Sens. Spat. Inf. Sci. ISPRS Arch. 2019, 42, 495-502. [CrossRef]

35. Hernandez-Lopez, D.; Felipe-Garcia, B.; Gonzalez-Aguilera, D.; Arias-Perez, B. An Automatic Approach to UAV Flight Planning and Control for Photogrammetric Applications. Photogramm. Eng. Remote Sens. 2013, 79, 87-98. [CrossRef]

36. Aicardi, I.; Chiabrando, F.; Grasso, N.; Lingua, A.; Noardo, F.; Spanò, A.T. UAV photogrammetry with oblique images: First analysis on data acquisition and processing. Int. Arch. Photogramm. Remote Sens. Spat. Inf. Sci. ISPRS Arch. 2016, 41, 835-842. [CrossRef]

37. Bolkas, D. Assessment of GCP Number and Separation Distance for Small UAS Surveys with and without GNSS-PPK Positioning. J. Surv. Eng. 2019, 145, 1-17. [CrossRef]

38. Tonkin, T.N.; Midgley, N.G. Ground-control networks for image based surface reconstruction: An investigation of optimum survey designs using UAV derived imagery and structure-from-motion photogrammetry. Remote Sens. 2016, 8, 786. [CrossRef] 
39. Agüera-Vega, F.; Carvajal-Ramírez, F.; Martínez-Carricondo, P. Assessment of photogrammetric mapping accuracy based on variation ground control points number using unmanned aerial vehicle. Meas. J. Int. Meas. Confed. 2017, 98, 221-227. [CrossRef]

40. Toth, C.; Jozkow, G.; Grejner-Brzezinska, D. Mapping with Small UAS: A Point Cloud Accuracy Assessment. J. Appl. Geod. 2015, 9, 213-226. [CrossRef]

41. Gašparovic, M.; Gajski, D. Two-step camera calibration method developed for micro UAV'S. Int. Arch. Photogramm. Remote Sens. Spat. Inf. Sci. ISPRS Arch. 2016, 41, 829-833. [CrossRef]

42. Yusoff, A.R.; Ariff, M.F.M.; Idris, K.M.; Majid, Z.; Chong, A.K. Camera calibration accuracy at different UAV flying heights. Int. Arch. Photogramm. Remote Sens. Spat. Inf. Sci. ISPRS Arch. 2017, 42, 595-600. [CrossRef]

43. Skarlatos, D.; Procopiou, E.; Stavrou, G.; Gregoriou, M. Accuracy assessment of minimum control points for UAV photography and georeferencing. In First International Conference on Remote Sensing and Geoinformation of the Environment (RSCy2013); International Society for Optics and Photonics: Bellingham, WA, USA, 2013; Volume 8795, p. 879514.

44. Peppa, M.V.; Mills, J.P.; Moore, P.; Miller, P.E.; Chambers, J.E. Automated co-registration and calibration in SfM photogrammetry for landslide change detection. Earth Surf. Process. Landf. 2019, 44, 287-303. [CrossRef]

45. Martínez-Carricondo, P.; Agüera-Vega, F.; Carvajal-Ramírez, F.; Mesas-Carrascosa, F.J.; García-Ferrer, A.; Pérez-Porras, F.J. Assessment of UAV-photogrammetric mapping accuracy based on variation of ground control points. Int. J. Appl. Earth Obs. Geoinf. 2018, 72, 1-10. [CrossRef]

46. Cucci, D.A.; Rehak, M.; Skaloud, J. Bundle adjustment with raw inertial observations in UAV applications. ISPRS J. Photogramm. Remote Sens. 2017, 130, 1-12. [CrossRef]

47. Gabrlik, P.; la Cour-Harbo, A.; Kalvodova, P.; Zalud, L.; Janata, P. Calibration and accuracy assessment in a direct georeferencing system for UAS photogrammetry. Int. J. Remote Sens. 2018, 39, 4931-4959. [CrossRef]

48. Brown, D. Decentering Distortion of Lenses. Photom. Eng. 1966, 32, 444-462.

49. Brown, D. Close-range camera calibration. Photogramm. Eng. 1971, 37, 855-866.

50. Fraser, C. Digital camera self-calibration. ISPRS J. Photogramm. Remote Sens. 1997, 52, 149-159. [CrossRef]

51. McGlone, R.; Mikhail, J.; Bethel, E.; Mullen, J. Manual of photogrammetry. In Photogrammetric Engineering and Remote Sensing; American Society for Photogrammetry and Remote Sensing: 425 Barlow Place, Bethesda: Rockville, MD, USA, 2004; Volume 79, p. 397.

52. Gneeniss, A.S.; Mills, J.P.; Miller, P.E. In-flight photogrammetric camera calibration and validation via complementary lidar. ISPRS J. Photogramm. Remote Sens. 2015, 100, 3-13. [CrossRef]

53. Honkavaara, E. In-Flight Camera Calibration For Direct Georeferencing Abstract: R. Int. Arch. Photogramm. Remote Sens. Spat. Inf. Sci. 2000, 2004, 166-172.

54. Harwin, S.; Lucieer, A.; Osborn, J. The impact of the calibration method on the accuracy of point clouds derived using unmanned aerial vehicle multi-view stereopsis. Remote Sens. 2015, 7, 11933-11953. [CrossRef]

55. Zhang, H.; Aldana-jague, E.; Clapuyt, F.; Wilken, F.; Vanacker, V. Evaluating the potential of post-processing kinematic (PPK) georeferencing for UAV-based structure-from-motion (SfM) photogrammetry and surface change detection. Earth Surf. Dyn. 2019, 7, 807-827. [CrossRef]

56. Eling, C.; Klingbeil, L.; Kuhlmann, H. Real-Time Single-Frequency GPS/MEMS-IMU Attitude Determination of Lightweight UAVs. Sensors 2015, 15, 26212-26235. [CrossRef]

57. Stöcker, C.; Nex, F.; Koeva, M.; Gerke, M. Quality assessment of combined IMU/GNSS data for direct georeferencing in the context of UAV-based mapping. Int. Arch. Photogramm. Remote Sens. Spat. Inf. Sci. ISPRS Arch. 2017, 42, 355-361. [CrossRef]

58. Tomaštík, J.; Mokroš, M.; Surový, P.; Grznárová, A.; Merganič, J. UAV RTK/PPK Method-An Optimal Solution for Mapping Inaccessible Forested Areas? Remote Sens. 2019, 11, 721. [CrossRef]

59. Gabrlik, P. The use of direct georeferencing in aerial photogrammetry with micro UAV. IFAC-PapersOnLine 2015, 28, 380-385. [CrossRef]

60. Benassi, F.; Dall'Asta, E.; Diotri, F.; Forlani, G.; Morra di Cella, U.; Roncella, R.; Santise, M. Testing Accuracy and Repeatability of UAV Blocks Oriented with GNSS-Supported Aerial Triangulation. Remote Sens. 2017, 9, 172. [CrossRef]

61. Rabah, M.; Basiouny, M.; Ghanem, E.; Elhadary, A. Using RTK and VRS in direct geo-referencing of the UAV imagery. NRIAG J. Astron. Geophys. 2018, 7, 220-226. [CrossRef]

62. Ekaso, D.; Nex, F.; Kerle, N. Accuracy assessment of real-time kinematics (RTK) measurements on unmanned aerial vehicles (UAV) for direct geo-referencing. Geo-Spat. Inf. Sci. 2020, 23, 165-181. [CrossRef] 
63. Štroner, M.; Urban, R.; Reindl, T.; Seidl, J.; Brouček, J. Evaluation of the georeferencing accuracy of a photogrammetric model using a quadrocopter with onboard GNSS RTK. Sensors 2020, 20, 2318.

64. Chiabrando, F.; Tonolo, F.G.; Lingua, A. Uav direct georeferencing approach in an emergency mapping context. the 2016 central Italy earthquake case study. Int. Arch. Photogramm. Remote Sens. Spat. Inf. Sci. ISPRS Arch. 2019, 42, 247-253. [CrossRef]

65. Losè, L.T.; Chiabrando, F.; Tonolo, F.G. Are Measured Ground Control Points Still Required in Uav Based Large Scale Mapping? Assessing the Positional Accuracy of an Rtk Multi-Rotor Platform. Int. Arch. Photogramm. Remote Sens. Spat. Inf. Sci. ISPRS Arch. 2020, XLIII-B1-2, 507-514.

66. Phantom 4 RTK User Manual, v2.2; DJI: Shenzhen, China, 2020.

67. D-RTK 2 User Guide; DJI: Shenzhen, China, 2020.

68. Taddia, Y.; Stecchi, F.; Pellegrinelli, A. Using dji phantom 4 rtk drone for topographic mapping of coastal areas. Int. Arch. Photogramm. Remote Sens. Spat. Inf. Sci. ISPRS Arch. 2019, 42, 625-630. [CrossRef]

69. Taddia, Y.; Stecchi, F.; Pellegrinelli, A. Coastal Mapping Using DJI Phantom 4 RTK in Post-Processing Kinematic Mode. Drones 2020, 4, 9. [CrossRef]

70. Zhao, B.; Li, J.; Wang, L.; Shi, Y. Positioning accuracy assessment of a commercial RTK UAS. In Autonomous Air and Ground Sensing Systems for Agricultural Optimization and Phenotyping V; International Society for Optics and Photonics: Florida, FL, USA, 2020; Volume 1141409, p. 8.

71. Cornaglia, P. Il Tempio di Diana: Giardini Italiani e Confronti Europei. 2010, pp. 247-264. Available online: https://www.torrossa.com/it/resources/an/4479316 (accessed on 30 September 2020).

72. Forlani, G.; Asta, E.D.; Diotri, F.; Morra, U.; Id, R.R.; Santise, M. Quality Assessment of DSMs Produced from UAV Flights Georeferenced with On-Board RTK Positioning. Remote Sens. 2018, 10, 311. [CrossRef]

73. Ćwiąkała, P. Testing Procedure of Unmanned Aerial Vehicles (UAVs) Trajectory in Automatic Missions. Appl. Sci. 2019, 9, 3488. [CrossRef]

(C) 2020 by the authors. Licensee MDPI, Basel, Switzerland. This article is an open access article distributed under the terms and conditions of the Creative Commons Attribution (CC BY) license (http://creativecommons.org/licenses/by/4.0/). 